\title{
Electromagnetic Interference to Flight Navigation and Communication Systems: New Strategies in the Age of Wireless
}

\author{
Jay J. Ely * \\ NASA Langley Research Center, Hampton, Virginia 32781
}

\begin{abstract}
Electromagnetic interference (EMI) promises to be an ever-evolving concern for flight electronic systems. This paper introduces EMI and identifies its impact upon civil aviation radio systems. New wireless services, like mobile phones, text messaging, email, web browsing, radio frequency identification (RFID), and mobile audio/video services are now being introduced into passenger airplanes. FCC and FAA rules governing the use of mobile phones and other portable electronic devices (PEDs) on board airplanes are presented along with a perspective of how these rules are now being rewritten to better facilitate in-flight wireless services. This paper provides a comprehensive overview of NASA cooperative research with the FAA, RTCA, airlines and universities to obtain laboratory radiated emission data for numerous PED types, aircraft radio frequency (RF) coupling measurements, estimated aircraft radio interference thresholds, and direct-effects EMI testing. These elements are combined together to provide high-confidence answers regarding the EMI potential of new wireless products being used on passenger airplanes. This paper presents a vision for harmonizing new wireless services with aeronautical radio services by detecting, assessing, controlling and mitigating the effects of EMI.
\end{abstract}

\section{Introduction to Aeronautical EMI: Lightning, HIRF and PEDs}

$\mathrm{I}_{\mathrm{f}}$

$\mathrm{t}$ can be said that aviation and radio have grown up together. Since the 1920's, radio technologies have faithfully and continually enabled the ever-expanding need for aerospace vehicle navigation and communication capability. Likewise, the need for reliable, secure communication, navigation and surveillance (CNS) and air traffic management (ATM) for aerospace vehicles has continually driven improvements in radio technology. As aviation has become more dependent upon radio for CNS, the effects of EMI have become ever more important. Since the 1920's, with few exceptions, radio spectrum for aeronautical radio services has been coordinated and protected by law, so as to minimize the potential of EMI from other radio services. However, EMI effects from lightning, electrostatic discharge and high intensity radiated fields (HIRF) from radars and broadcast transmitters have resulted in numerous aviation incidents and accidents over the years, and as a result, are now carefully considered in all aspects of design and certification of modern avionics. Figure 1 shows an overview of the electromagnetic environment in which a typical airplane flies.

While the lightning environment has not changed since the inception of aviation, flight operations now occur in all weather conditions. In 1938, the National Advisory Committee for Aeronautics (NACA) established the Subcommittee of Aircraft Safety, Weather and Lightning Experts to study lightning effects on aircraft and determine what additional protective measures were needed. There is an interesting history of lightning strikes to airplanes, sometimes with catastrophic effects. Today, lightning strikes have minimal safety impact upon airplanes due to wellestablished FAA lightning protection regulations. The textbook "Lightning Protection of Aircraft" provides a thorough technical guide to protecting aircraft from the effects of lightning, and an excellent history and development of FAA lightning protection regulations. ${ }^{1}$

In the early 1960's, it became evident that compact radio receivers, enabled by new transistor circuitry, and carried on board airplanes by passengers, could disrupt the VHF Omniranging (VOR) and other navigation systems.

\footnotetext{
${ }^{*}$ Research Engineer, Electromagnetics \& Sensors Research Branch, Mail Stop 130. 
To address this concern, the Radio Technical Commission for Aeronautics (RTCA) formed Special Committee 88. Their report, RTCA/DO-119, "Interference to Aircraft Electronic Equipment from Devices Carried Aboard" was published in $1963 .{ }^{2}$ This early effort resulted in FAR 91.19, controlling the use of PEDs on board aircraft and recommended prohibiting the operation of portable radios during flight, and set the stage for restrictions on passenger-carried PEDs that are still in effect today.

By the 1970's, it also became evident that new digital flight control systems needed to be hardened to the effects of HIRF emanating from broadcast towers, radars, and point-to-point radio links. In the United States, the Department of Defense began to apply interface standard and system requirements for the control of EMI on aircraft systems. ${ }^{3,4}$ These requirements are currently accompanied by numerous EMI-related handbooks relating to RF environment definition, procurement guidelines, hazards, grounding, bonding and shielding. For commercial aviation, the FAA worked with the RTCA to standardize environmental conditions and test procedures for airborne equipment. $^{5}$ Since the 1980's, NASA has supported several studies documenting HIRF and EMI related events reported by airplane flight crews. ${ }^{6,7}$

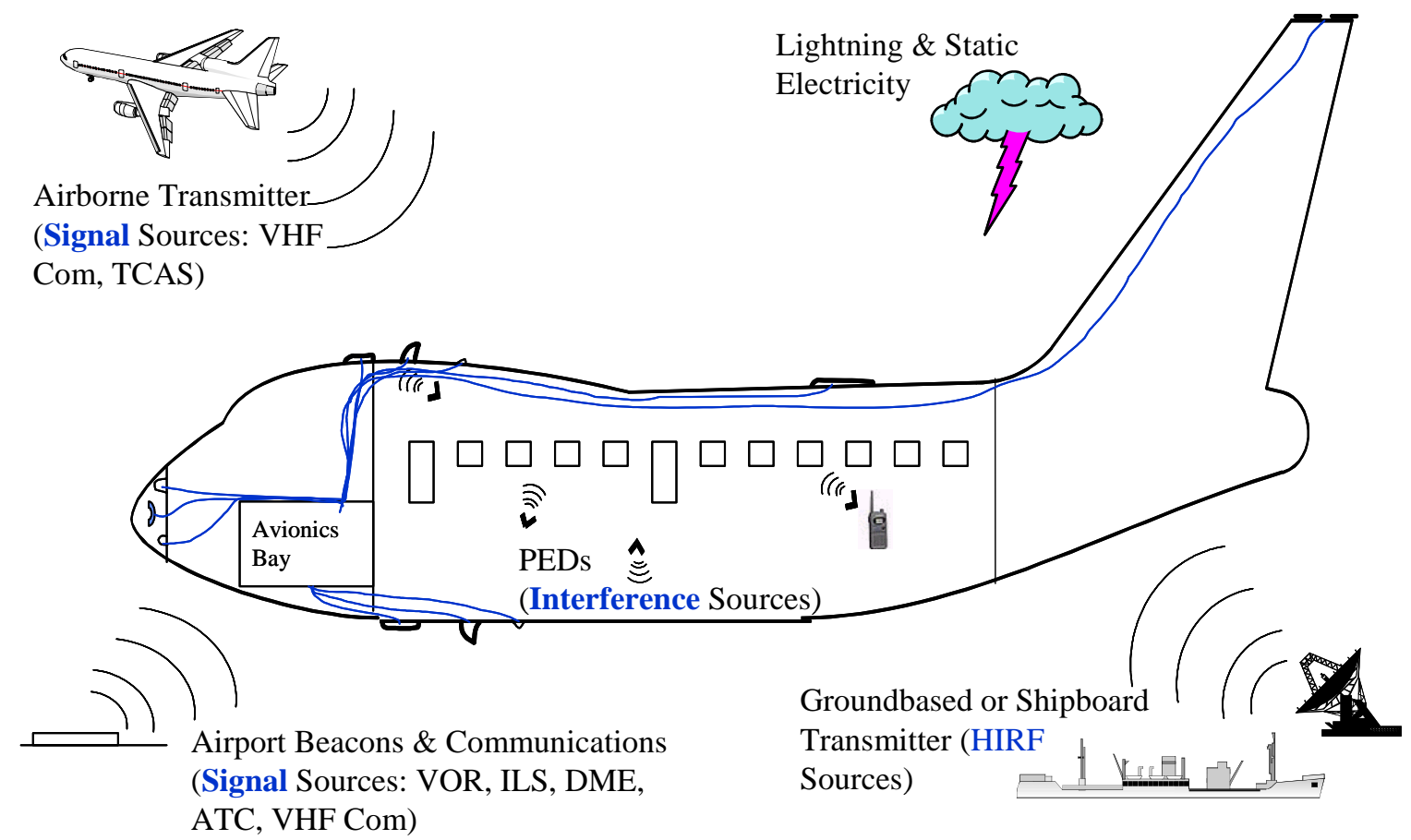

Figure 1: Electromagnetic threats to aircraft systems

There are three basic elements to any EMI problem: Source, Path and Victim. This paper focuses upon the dynamic EMI situation created by introducing intentionally-transmitting PEDs (“T-PEDs", ie. cellular phones, handheld radios, IEEE 802.11, etc.) into the airplane cabin. Because PEDs and T-PEDs are normally operated by battery power when used on board airplanes, the path is primarily radiated, rather than conducted. (Some airplanes are equipped with in-seat power for passengers, however the airplane supply systems are well regulated and controlled to prevent conducted EMI to the aircraft electronic systems.) Given the physical size and transmit power limitations of such devices, the primary EMI concern is for aircraft electronic systems (Victim), particularly CNS radios.

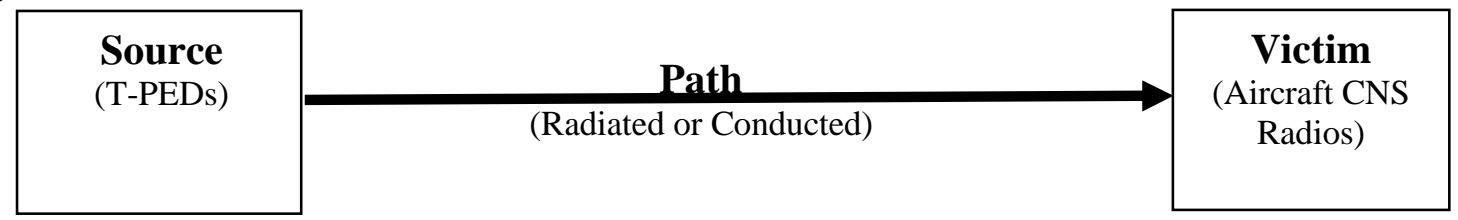

Figure 2: Three basic elements to any EMI problem. 2

American Institute of Aeronautics and Astronautics 


\section{On-Board Wireless: EMI Focus on Communication and Navigation Systems}

Until the past 10 years or so, most airplane passengers were quite happy to leave their T-PEDs at home, packed away, or at least turned off while on board. The explosive proliferation of wireless voice and data products, and the increasing reliance of travelers upon them, now creates a serious safety concern for airlines and the FAA. Wireless transmitters are increasingly being integrated into multifunction packages, often making it difficult for flight crews and passengers to identify them as intentional transmitters.

\section{A. PED EMI Reports}

The most widely used, publicly available source of information about crew reports of airplane PED EMI events is the NASA aviation safety reporting system (ASRS), which is administered under a memorandum of agreement with the FAA. In March 2001, Ross reported a detailed analysis of ASRS data relating to PED EMI reports occurring from 1986 to $1999 .{ }^{8}$ The study provided significant graphical analysis of PED types, airplane types, phase of flight where incidents occurred, aircraft systems affected, whether incident was annunciated to the crew, and degree of severity of the EMI event. Figure 3 (bottom) shows a graphical comparison of the number of PED EMI incidents attributed to different kinds of PEDs. Clearly, mobile phones and laptop computers were the most likely PEDs to be attributed as having caused an EMI incident. Figure 3 (top) shows a comparison of the aircraft systems affected by PED EMI. Because of their necessary sensitivity to RF signals, aircraft CNS systems are expected to have the highest sensitivity to PED EMI. Figure 3 confirms this expectation with alarming clarity.

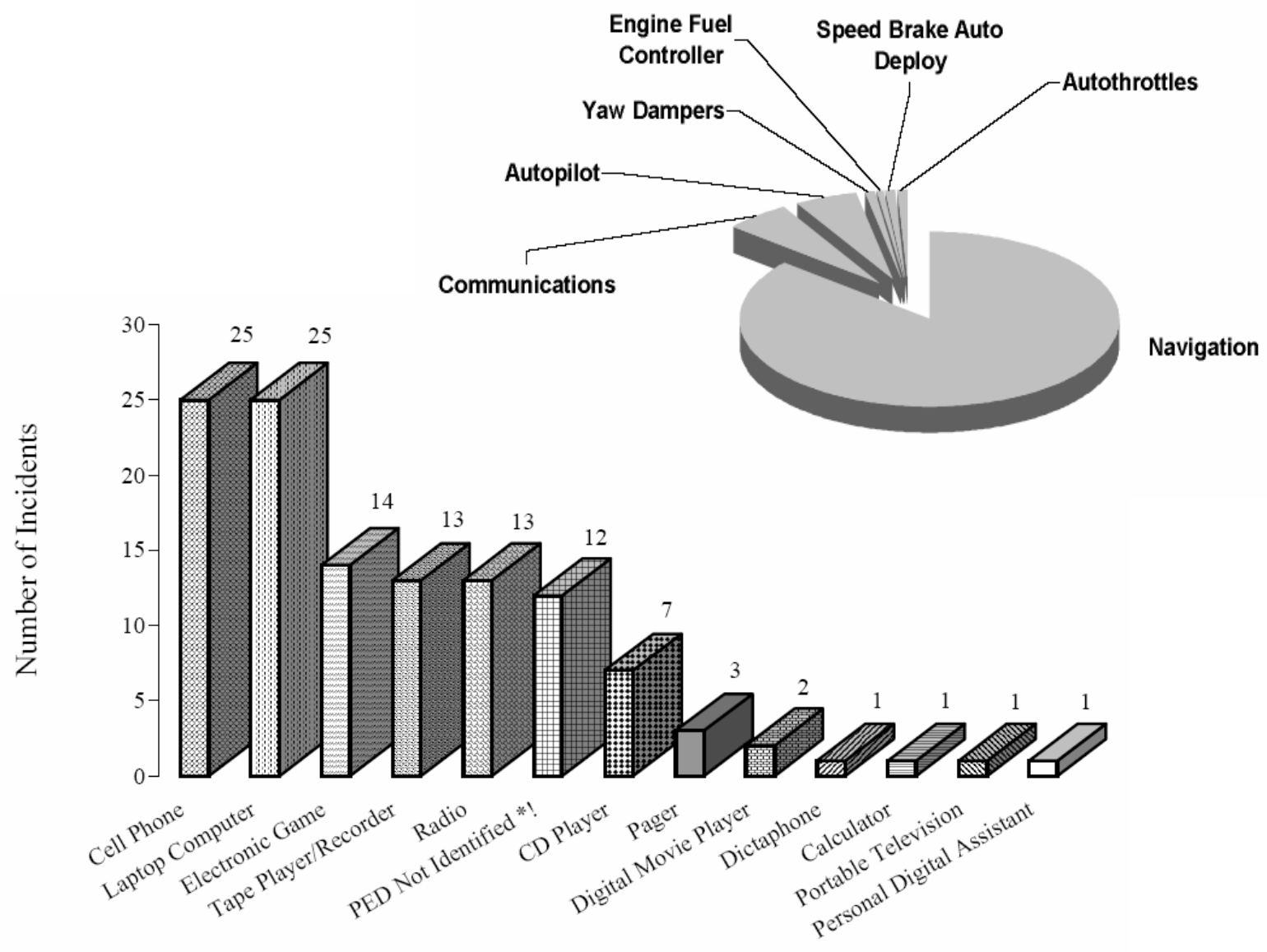

Figure 3: NASA ASRS study from 1986 to 1999

(Bottom) PEDs affecting aircraft systems (Top) Aircraft systems affected

American Institute of Aeronautics and Astronautics 


\section{B. U. S. and European Government EMI Regulations}

\section{FCC \& IEC Rules for Products}

In the U. S., the Federal Communications Commission (FCC) provides guidance for allowable signal emissions from consumer devices. These are published and available on the Internet, in the U. S. Code of Federal Regulations (CFR), Title 47 "Telecommunication". Within Title 47, there are numerous "Parts" and "Sections" that address the full range of available product types. In Europe, the International Electrotechnical Commission (IEC) provides guidance for allowable signal emissions from consumer devices. Measurement methods and test limits are provided in the IEC CISPR 22 publication. To promote free trade and facilitate technology transfer across international boundaries, the US and European Union (EU) have Mutual Recognition Agreements (MRA) which harmonize measurement processes and test limits for spurious radiated emissions. Most other nations recognize or adopt either the US or EU requirements applicable to PEDs. In any case, these product standards address devices intended for use in residential, commercial, industrial or business environments. Both the US and EU further designate "Class A" and "Class B", where Class A devices are not intended for use in residential environments. Most consumer products that are not intended to transmit RF power are certified to the more rigorous Class B requirements. TPEDs however, may include mobile phones, wireless local area networks (LANs), Citizen's Band (CB) radios, Family Radio Service (FRS) transceivers, General Mobile Radio Service (GMRS) transceivers, RFID tags and many other devices. FCC rules for spurious radiated emissions of T-PEDs very widely, and are addressed in differenct sections of the CFR.

\section{FAA Rules for PEDs on Airplanes}

In the US, the FAA provides guidance for allowable signal emissions from aircraft electronic systems. These are not directly stated in the US CFR (as with the FCC limits for consumer devices). Instead, 14CFR91.21 states that PEDs

"may be used if the aircraft operator has determined that they will not cause interference with the navigation or communication system of the aircraft on which it is to be used"10.

Further guidance is provided by Advisory Circular 91.21-1A, which states that designing and testing PEDs in accordance to RTCA/DO-160D ${ }^{11}$ may constitute one acceptable method allowing their operation on board aircraft ${ }^{12}$.

RTCA/DO-160D, Section 21 contains measurement procedures and test limits to determine whether electronic equipment emits excessive RF signals when installed in a particular location. The requirements are "harmonized" with EUROCAE ED-14 ${ }^{13}$, and therefore technically identical, and acceptable to Europe's Joint Aviation Authorities (JAA). Various equipment categories are defined in terms of location and separation between the equipment and aircraft radio antennas.

Unfortunately, neither RTCA/DO-160 nor EUROCAE ED-14 address equipment (PEDs) that are carried on board by passengers.

\section{RTCA and EUROCAE PED Guidance}

\section{RTCA/DO-119}

In 1963, RTCA/DO-119, "Interference to Aircraft Electronic Equipment from Devices Carried Aboard" recommended prohibiting the operation of portable radio and television receivers during flight, and set the stage for restrictions on passenger-carried PEDs that are still in effect today ${ }^{14}$. The study also addressed hearing aids and portable dictating and recording machines. Most interestingly, the committee also recommended that specific radiated emission limits be met for PEDs to be used on board airplanes, and furthermore, that such devices be

\footnotetext{
"suitably and conspicuously marked to provide a clear indication to flight crews that such devices have been determined to be suitable for use aboard aircraft; and further: That such devices also be suitably marked internally with a 'WARNING' legend to the effect that any modifications of circuitry, or the use of replacement parts which do not meet the manufacturers specifications automatically voids the authorization for use of the device aboard aircraft."
}

The FCC however did not impose any regulatory limits on the radiated emissions of PEDs, in general, as a result of the DO-119 recommendations. 


\section{RTCA/DO-199}

By the early 1980's many airline passengers began inquire about the use of laptop computers, video recorders, electronic games, calculators, paging receivers, medical devices, and even cellular telephones while on board. Various airlines had differing policies about the allowance for use of different types of PEDs. Because some air carriers prohibited the use of laptop computers on board, some computer magazines began to suggest that their readers avoid particular airlines. In 1983, this lead to the Director of Quality Assurance and Chief Engineer of Eastern Airlines requesting the RTCA to "generate a Minimum Operational Performance Standards document against which manufacturers (of computers and other portable electronic devices) marketing their products for airborne use, could test and label them as meeting this standard in a manner similar to the Underwriters Laboratory sign of approval.” Soon thereafter, RTCA Special Committee 156 was formed.

On September 16, 1988, the Special Committee (SC) 156 report, RTCA/DO-199 "Potential Interference to Aircraft Electronic Equipment from Devices Carried Aboard" was published. ${ }^{15}$ The report compiled nearly five years of extensive efforts including operator surveys, aircraft radio susceptibility testing, aircraft coupling measurements, PED emission testing, evaluation mitigation strategies such as shielding of windows, probability of disruption analysis, and proposed radiation limits. The effort focused primarily on non-transmitting PEDs.

The committee concluded that PED EMI to aircraft radios CAN occur, however the probability is small.

RTCA/DO-199 made several important recommendations:

- Acceptable limits of radiation and associated test methods for PEDs be established

- The FCC specify a new classification for PEDs that may be operated on aircraft

- $\quad$ The FAA initiate a regulatory project to revise FAR 91.19

- Standardize reporting of suspected EMI be implemented by aircraft operators

The FAA subsequently adopted the proposed RTCA/DO-199 guidance, which resulted in the allowance of hearing aids, heart pacemakers and electronic watches by passengers, but also the prohibition of use of T-PEDs. The guidance went further to recommend that some non-transmitting PEDs may be used during cruise flight (not takeoff and landing), such as audio or video recorders \& playback devices, electronic entertainment devices, computers and peripheral devices, calculators, FM receivers, TV receivers, and electronic shavers.

\section{RTCA/DO-233}

In 1992, the RTCA received an FAA request to revisit the issue of PEDs carried on board airplanes. This FAA request was in response to a House Transportation Appropriations Bill that year that desired to resolve questions about "recently devised PEDs, multiples of similar and dissimilar PEDs, and intentional electromagnetic radiators such as remote control devices and cellular telephones." On September 23, 1992, the formation of RTCA Special Committee 177 was approved.

On August 20, 1996, RTCA/DO-233 “Portable Electronic Devices Carried on Board Aircraft” was published. ${ }^{16}$ RTCA/SC-177 extended the technical work of SC-156 on nearly every front. The 30 PED EMI reports used by SC156 were supplemented with 34 more from the NASA ASRS, 40 more from the International Air Transport Association (IATA) and 33 more to SC-177 directly. The FCC methodology for measuring PED emissions was modified to be more compatible with avionics-type measurements. The methodology for measuring the path loss between PEDs and airplane radio receivers now included swept-frequency approach, and was much more clearly and thoroughly defined. The report considered both antenna-coupled "front door" and cable/aperture-coupled "back door" interference to aircraft systems. Also, the report included analysis of Interference Probability and Operational Interference Criteria. Unfortunately, SC-177 was unable to consider devices considered as intentional radiators (ie. T-PEDs). The committee concluded that:

- PED EMI to aircraft systems CAN occur, however multiple independent conditions must be present.

- All PED operations should be restricted during critical phases of flight, as it is impractical for an aircraft operator to determine whether any particular PED will not cause interference.

RTCA/DO-233 made several important recommendations:

- Prohibit the operation of T-PEDS on airplanes unless testing has been conducted to ascertain their safe use.

- Prohibit the operation of all PEDs during critical phases of flight.

- Continued testing of PEDs for spurious radiated emissions. 
- A public education campaign should be initiated by the airline industry and aircraft manufacturers to alerth the public to the potential for harmful EMI to occur when PEDs are used on board airplanes.

- $\quad$ PED detection devices (installed or portable) should be designed and tested in commercial airplanes.

The FAA subsequently adopted the first two recommendations into FAR 91.21a.

\section{EUROCAE/ED-118}

After the publication of RTCA/DO-233, it became more and more evident, both in Europe and in the U. S. that the use of mobile phones, wireless LANs and wireless personal area networks (PANs) on board airplanes needed to be considered. In December 2000, Intel released a report "Safety Evaluation of Bluetooth Class ISM Band Transmitters on board Commercial Aircraft", which recommended that FAA and JAA regulations be modified to specifically allow Bluetooth devices to be used during flight. In October 2001, the JAA issued Leaflet No. 29 "Guidance Concerning the Use of Portable Electronic Devices on board Aircraft", which specifically permits Bluetooth transmitters to be operated during non-critical phases of flight.

In early 2001, the European Organisation for Civil Aviation Equipment (EUROCAE) formed Working Group 58 with the following three objectives:

- To review the EMC issues related to the use of new technology PEDs and related installed services on aircraft by evaluation and comparison of existing studies, measurement of data as necessary, and production of a report.

- To propose technical and non-technical solutions for the operation of PEDs on board aircraft for the aviation community, including standards and guidelines as appropriate.

- To provide guidelines to non-aviation standardization forums, in order to help them assist in the maintenance of safety on board aircraft.

The working group was specifically tasked to "consider both intentional and unintentional radiations from PEDs, and their coupling to electronic systems and antennas." EUROCAE WG-58 has been the focal point of extensive collaboration and technical work on PED EMI, and continues to meet regularly. Many of the WG-58 members regularly participate in RTCA/SC-202 meetings and committees also. The EUROCAE WG-58 final report, ED-118 was released in November $2003^{17}$. Some highlights of the ED-118 findings are listed here:

- The primary coupling risk for interference from PED spurious radiated emissions is through the system antennas in the operational frequency bands of the aircraft receivers. PED's should continue to be switched OFF during take off and landing to avoid possible EMI.

- Low power intentional transmitters represent the same low risk as unintentional transmitters. Therefore, passenger and crew use of these low power intentional transmitters may be allowed on the aircraft types analyzed on a case by case basis.

- Recommend the prohibition of the use of any high power intentional emitters (EIRP of more than $100 \mathrm{~mW}$, like two way radios, satellite telephones, cellular telephones) during all phases of flight, unless their safe use is demonstrated.

- A harmonization of the announcement between airlines and countries and an improvement of airline announcements (several times, at better moments etc...) should be done.

- The use of PED detectors has not been retained as appropriate because the remaining risk that arises from the potential unknown effects that the detectable devices may have to the aircraft systems, is considered lower than the adverse effects that the technical and procedural problems of using a detector could develop on the conduct of the flight.

- A concern is related to the introduction of a variety of PEDs including transmitters having owners, not being aware of those transmitters or not in a position to disable them. Consequently, PED evolution is a very important concern for any aircraft and hence, a continuous market monitoring is considered necessary, to check wireless power emission and integration inside common PEDs.

- It is recommended that all standardization teams take the uncontrolled usage of PEDs onboard aircraft into account and take action to assure the safe operation of aircraft.

- During this analysis the need for further studies and the continuous work on PED interference issues has been identified. Studies should be related to the more detailed understanding of the interference risk in relation to cavity effects, short distance influences, comparison between different EMC measurement 
procedures used in standards, statistical analysis of cumulative effects, UWB effects, potential interference caused by uncontrolled demodulation of signals, and other knowledge gaps as identified in the report.

- Recommended the development of specific guidance to airframe manufacturers, PED manufacturers, airlines and the traveling public for the use of PEDs. The working group therefore recommended the joint development of additional guidance with RTCA SC202 and the creation of a common document based on ED118.

\section{RTCA/DO-294}

In early 2003, the FAA requested that the RTCA initiate a new Special Committee to focus upon intentionally transmitting PEDs. On March 21, 2003, the RTCA issued their first Terms of Reference for Special Committee 202. RTCA SC-202 was tasked with developing guidance related to the use of portable electronic devices (PEDs) on board air carrier aircraft. The guidance is intended to provide a means for authorities, aircraft operators, aircraft manufacturers, PED manufacturers, and others as appropriate, to determine acceptable and enforceable policies for passenger and crew use of PEDs. The primary focus for SC-202 is upon PEDs that transmit intentionally. The work was divided into two phases:

- In Phase I, a near-term PED technology assessment, the committee focused on PED technologies that currently exist.

- In Phase 2, a longer-term PED technology assessment, the committee will focus on emerging PED technologies, for example ultra-wideband devices or pico-cells for telephone use on board aircraft.

During the first SC-202 meeting in May 2003, SC-202 divided the efforts in to four working groups. Working Group 1 focused upon categorizing classes of PEDs, standards for characterization of their radiated emissions, and compilation of RF emissions of representative devices. This group also addressed device failure modes that affect RF emissions, and provide design guidance for making new devices that are more "aircraft friendly". Working Group 2 focused upon aircraft coupling and RF environment testing and analysis. Working Group 3 focused upon aircraft system susceptibility to radiated PED emissions. Working Group 4 worked with the other 3 groups to generate a risk assessment and compile documentation for the guidance document deliverable products of SC-202.

Phase I was completed with the publication of DO-294, Guidance on Allowing Transmitting Portable Electronic Devices (T-PEDs) on Aircraft, issued October 19, 2004 ${ }^{18}$. The DO-294 findings and recommendations were extensive. They are summarized here:

- The report provides a standard process for determining if the use of T-PEDs on aircraft could be allowed, and acknowledged that current operational procedures instructing passengers to turn off all PEDs during critical phases of flight, and turn off all T PEDs during all phases of flight are not fully effective.

- It may not be adequate to apply MOPS requirements directly when assessing individual aircraft system susceptibility.

- The approach taken to aircraft RF protection assumes that an EMI environment would be presented to the aircraft from outside the fuselage or from devices permanently installed on the airframe. On-board use of $T$ PEDs is introducing a new EMI source that could affect the performance of aircraft systems and requires a reassessment of aircraft RF protection methods and procedures.

- There is insufficient data concerning path loss, transfer function, and coupling to characterize all aircraft types and configurations.

- One of the difficulties associated with potential introduction of T PEDs to commercial aircraft is the lack of consistent T PED marking or indication for its operating state, apparent to the users and the cockpit and cabin crewmembers.

- Most emissions from T PEDs are significantly lower than the applicable FCC spurious emissions limits. However, analysis performed during the development of this report confirmed that T PED spurious emissions at the applicable FCC spurious emission limits could create a level of interference sufficient to adversely affect the operation of some critical aircraft systems if the T PED is operated onboard the aircraft. This analysis confirms earlier conclusions reached in DO-199 and DO-233.

- The system design for new CNS techniques and technologies should consider the impact of ubiquitous EM energy. 
- In the long term, test standards such as ED14/DO160 Section 20 should be revised to account for the back door interference environment created by on-board PEDs, including T PEDs. Minimum test level requirements should be established to account for this new interference environment.

- The FCC should review 47CFR and the sections defining emissions limits for mobile and portable devices (e.g. Part 15, Part 22, Part 24, Part 25, and Part 90 and others, as appropriate) with the aim of introducing appropriate limits in the CNS bands for those devices that may be commonly operated on-board aircraft. In accordance with the Terms of Reference, recommended RF emission limits will be developed as part of the SC 202 Phase II activity.

- A repository of isolation, path loss, transfer function, and EM propagation behavior within aircraft types should be developed. To the maximum extent possible, the data should be consistently measured, account for variations of aircraft type and configuration, and be suitably documented. This recommendation recognizes the practical difficulties in establishing and maintaining such a repository.

- A repository of T PED (and PED, in general) incidence reports should be established, along with a process and mechanism for feedback of improvements into the regulatory and operational processes. These incident reports should not be limited to EMI to essential or critical systems, but document any EMI to any aircraft system.

- Operators desiring to allow T PED operations on-board aircraft should follow the process defined in this document in order to develop appropriately detailed information concerning the risks, risk mitigation, and residual effects of T PED emissions on aircraft operations. Operators desiring to allow PED or T PED use onboard aircraft should follow those processes defined in this document for mitigation of human factors effects on aircraft operations.

- Aircraft and equipment manufacturers should consider T PED usage in the interior of the fuselage as a source of RF emissions, and design and test appropriately in order to demonstrate compliance with appropriate regulations.

- Aircraft manufacturers should include T PED interference effects in flight safety analysis as part of aircraft certification.

- Aircraft manufacturers and aircraft operators should collect and make available appropriate data for current and future aircraft. Path loss data should be provided as an inherent element of the aircraft production or modification process.

- The aviation industry should endorse, harmonize, and exploit the improved status and control mechanisms for T PED devices as such mechanisms become available. These mechanisms are expected to result from the actions of the electronics industry and other interested stakeholders, such as the recommendations document to the consumer electronics industry entitled "Recommended Practice - Status Indicator for and Control of Transmitters in Portable Electronic Devices (PEDs)," which is currently under development by the PEDs Working Group (hosted by the CEA).

- Avionics manufacturers should study the prevailing intentional and unintentional EM signatures of PED technologies for guidance on developing isolation criteria between the interior of the cabin and sensitive equipment.

- All commercial aircraft should have a consistent, uniform, and ubiquitous indicator showing when use of PEDs or T PEDs is permitted. This visual indicator should be omni-lingual; ideally a symbol accessible to an international audience and coordinated with the CEA symbol developed in response to the above recommendation.

- Aircraft manufacturers and operators should utilize the recommended practices when determining front door IPL. Use of the recommended practices will ensure that consistent, repeatable results are obtained that are directly comparable.

- Care should be exercised when utilizing available path loss data for similar aircraft type comparisons and assessments.

- Additional efforts are needed to better understand and quantify back door coupling on existing and new aircraft types. Collecting data to quantify the back door coupling concerns should be organized and pursued.

- ICAO-member States' air-safety investigative authorities should provide awareness training to their investigators regarding what circumstance[s] the performance of an aircraft involved in an incident or accident could be related to electromagnetic interference and provide guidance (such as checklists and resource contact information) for an effective assessment of potential EMI involvement in an occurrence scenario. 
- Significant additional effort should be applied to better quantify the multiple equipment factor (MEF). Approaches may consider coupling path, failed T PEDs, T PED transmit signal protocols and aircraft receiver characteristics.

\section{NASA LaRC Collaborative EMI Work with Universities, Airlines, RTCA \& FAA}

\section{Airplane Coupling Path Measurements}

Figure 4(a) illustrates typical radio receiver interference coupling paths and Figure 5(b) shows a setup for conducting interference path loss (IPL) measurements. IPL is defined as the measurement of the radiated field coupling between passenger cabin locations and aircraft communication and navigation receivers, via their antennas. The setup shows a tracking source is used to provide RF power to the transmit antenna, and a spectrum analyzer is used to measure the signal received by the aircraft antenna. The frequency-coupled spectrum analyzer and tracking source pair allows for frequency sweeps, resulting in more thorough measurements and reduced test time. Swept CW was preferred over discrete frequency measurement, according to RTCA/DO-233. A pair of test cables is used to connect the instruments to the aircraft antenna cable and to the transmit antenna. An optional amplifier may be needed to increase the signal strength depending upon the capability of the tracking source and the path loss level. A preamplifier may be needed in the receive path near the spectrum analyzer for increased dynamic range. This preamplifier (not shown in Figure 4.1-3) may be internal to the spectrum analyzer.

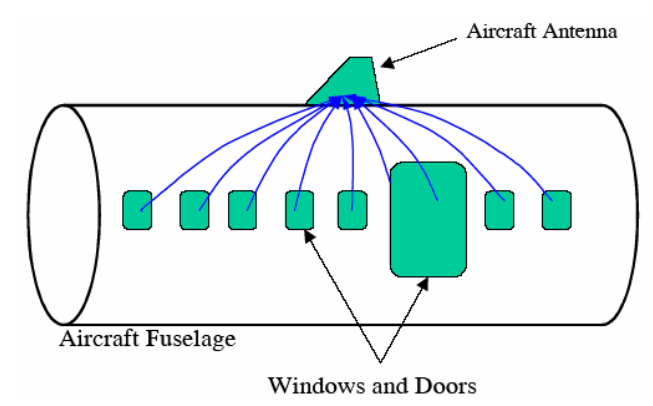

Figure 4: (a) A typical radio receiver interference coupling path for a top mounted aircraft antenna. (b) A typical setup for conducting an IPL measurement.

From 1996 to 1998, the FAA Office of Aviation Security R\&D conducted a multiyear assessment of the potential use of on-board EMI to upset critical and essential aircraft functions. The effort utilized engineering expertise from Veda Incorporated and Eagles Wings Incorporated (EWI) to perform measurements on a FAA CV580 airplane located at the William J. Hughes Technical Center in Atlantic City, New Jersey. The tests established the IPL measurement techniques used by RTCA DO-233, and resulted in several important findings. Some of the findings are listed here ${ }^{19}$ :

- Reflections from wing and engine are not significant to passenger cabin-to-aircraft antenna coupling data. 
- Effect of coupling through cockpit door was determined to be insignificant for VOR, VHF Com, UHF Com, Distance Measuring Equipment (DME) and the Global Positioning System (GPS) aircraft radios. The effect of Glideslope (ILS Glideslope) coupling through the cockpit door was determined to be secondary to coupling through passenger cabin windows.

- Mode Stirring techniques were found to be helpful when obtaining data at limited measurement locations.

- Applying aluminum tape to all aircraft windows resulted in up to $35 \mathrm{~dB}$ increase in IPL.

- Direct interference effects were demonstrated to aircraft VOR, VHF Com, UHF Com, Glideslope and GPS when using a low-powered transmitter (spectrum analyzer tracking source).

In the Fall of 1999, NASA extended the FAA work with Eagles Wings Incorporated (EWI) to perform IPL measurements on B747-400 airplanes located in Las Vegas, Nevada, and San Francisco California. This work was extended to evaluate the effect of PED signal propagation over the curved portion of different diameters of aircraft fuselages. Some of the findings are listed here. ${ }^{20}$

- Identified nose-mounted antennas on the B-747 (Localizer, Glideslope) to have very low coupling loss to the passenger cabin lower front deck.

- Identified top-mounted antennas on the B-747 (TCAS, ATC, VHF Com, SATCOM) to have very low coupling loss to the upper passenger cabin area.

- Found that IPL from passenger locations outside the airplane (ie. jetways and stairs) are often lower than from inside the airplane.

- Coupling from the passenger cabin to aircraft antennas is minimized when it occurs over fuselage sections of lower curvature.

- IPL measurements should be performed on smaller regional jets and turbo props.

In the Spring of 2000, EWI teamed with Delta Airlines to address a NASA Research Announcement, and proposed a study entitled "Operational Malfunction Mitigation on Commercial Aircraft Communication/Navigation Systems due to Close-in ElectroMagnetic Interference Threats”. In July 2000, NASA Langley research center entered a Cooperative Agreement with Delta airlines to measure RF coupling from the passenger cabins of various aircraft types. Additional data was obtained to determine the cause of excessive antenna-to-receiver path losses found in a previous measurement program. Airport frequency spectrum environment were measured in ramp/boarding/lounge areas outside the aircraft. Ambient RF environment data was collected from $20 \mathrm{MHz}$ to 2.5 GHz. Methods of measuring RF emissions from PEDs were evaluated. PED threat levels and aircraft coupling factors were compared to operationally required com/nav signal levels to determine the potential for interference. Technical findings from the measurement and analysis effort were used to develop improved operational procedures and policies for identifying, resolving and mitigating PED EMI conditions.

In 2003, the agreement was modified to facilitate airline support of RTCA SC-202 activities, to collect more IPL data on multiple B-757 airplanes, to perform a statistical analysis of IPL, to collect signal level data from taxiways in typical airport environments, and to collect further radiated emission data from PEDs. The cooperative agreement was extended to March 2005, and provided significant useful data to RTCA SC-202 and practical insight into airline maintenance and flight operations, as well as an understanding of airline perspective regarding EMI issues (ie. aircraft certification and maintenance, fault isolation, troubleshooting and recovery, and incident reporting). Several of the Delta reports are available on the NASA Technical Report Server website. ${ }^{21}$ Figure 5 shows a sampling of measurement activity and data related to the Delta Airlines Testing. 


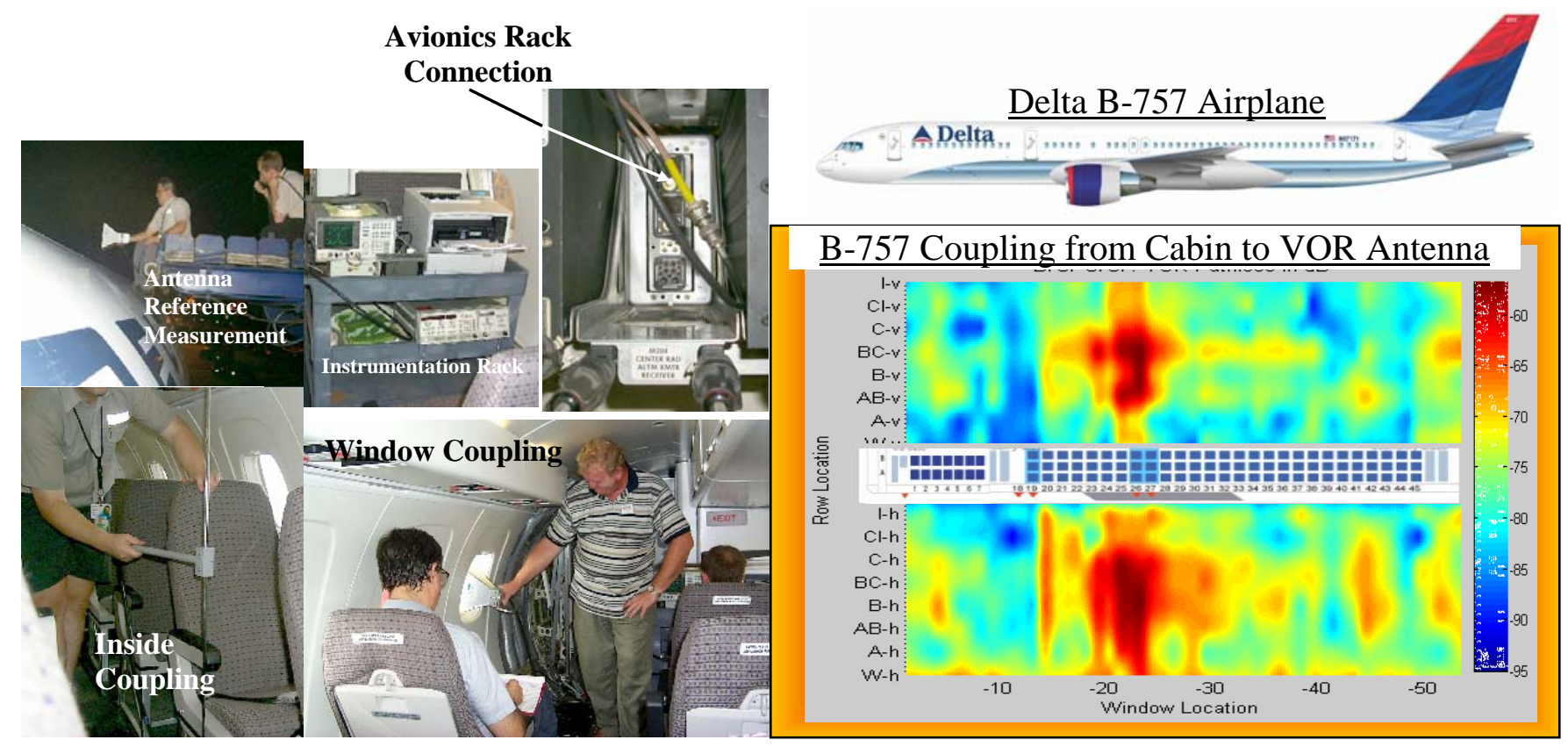

Figure 5: Left: Instrumentation setups and measurements of IPL. Right: IPL data collected along a crosssectional plane of the passenger cabin of a B-757 airplane.

On September $11^{\text {th }}$, 2001, the terrorist attack caused many airlines to park flight-ready airplanes at desert storage facilities. During the Spring and Summer of 2002, this situation provided an opportunity to extend the available database of radio frequency (RF) coupling losses from various passenger-cabin locations. Evaluation of the NASA/Delta/EWI measurements had identified a concern that path loss data collected and reported by different personnel, on different but similar airplanes may have some degree of variability.

- Duplicate sets of path loss data were obtained on multiple, identical Boeing 737 and Boeing 747 aircraft, to establish repeatability of the measurement process and to identify any differences related to subtle aircraft configuration changes.

- Path loss measurements were also performed using an alternate, electrically small biconical antenna for the VHF band. Previously, all IPL measurements had been performed with tuned dipole antennas, which are not very rugged, and are too large to be easily manipulated in most airplane passenger cabins.

- An Eclypse handheld Standing-Wave-Reflectometer was demonstrated to reveal aircraft radio cable and antenna faults. The device required minimal operator training, and showed definite promise for allowing simple assessment of aircraft RF pathways without antenna removal (which is operationally expensive). The Eclypse meter was a direct product of commercialization of NASA technology for troubleshooting cable faults on space shuttle orbiters (NASA Tech Briefs Technical Support Package KSC-11866, U.S. Patent \#5,977,773).

- Conductive door-seam treatments and window films were evaluated to test aircraft modifications for minimizing interference coupling from passenger transmitters to aircraft radios via their antennas.

- In a supplemental test, Ultrawideband (UWB) electromagnetic interference (EMI) effects were observed on the Air Traffic Control Radio Beacon System (ATCRBS), Traffic Collision Avoidance System (TCAS), Instrument Landing System (ILS) Localizer and ILS Glideslope aircraft systems ${ }^{22,23}$. The interference effect was observed when operating the UWB device at numerous locations within the passenger cabin. A video was made of the interference. This lead to an extensive direct EMI effects UWB testing program discussed below. 
Data from this effort has continued to provide useful insight into airplane IPL characteristics for computational modeling, estimation of multiple equipment factor, statistical analysis, evaluation of shielding techniques, and comparison to other airplanes. ${ }^{24,25,26,27}$

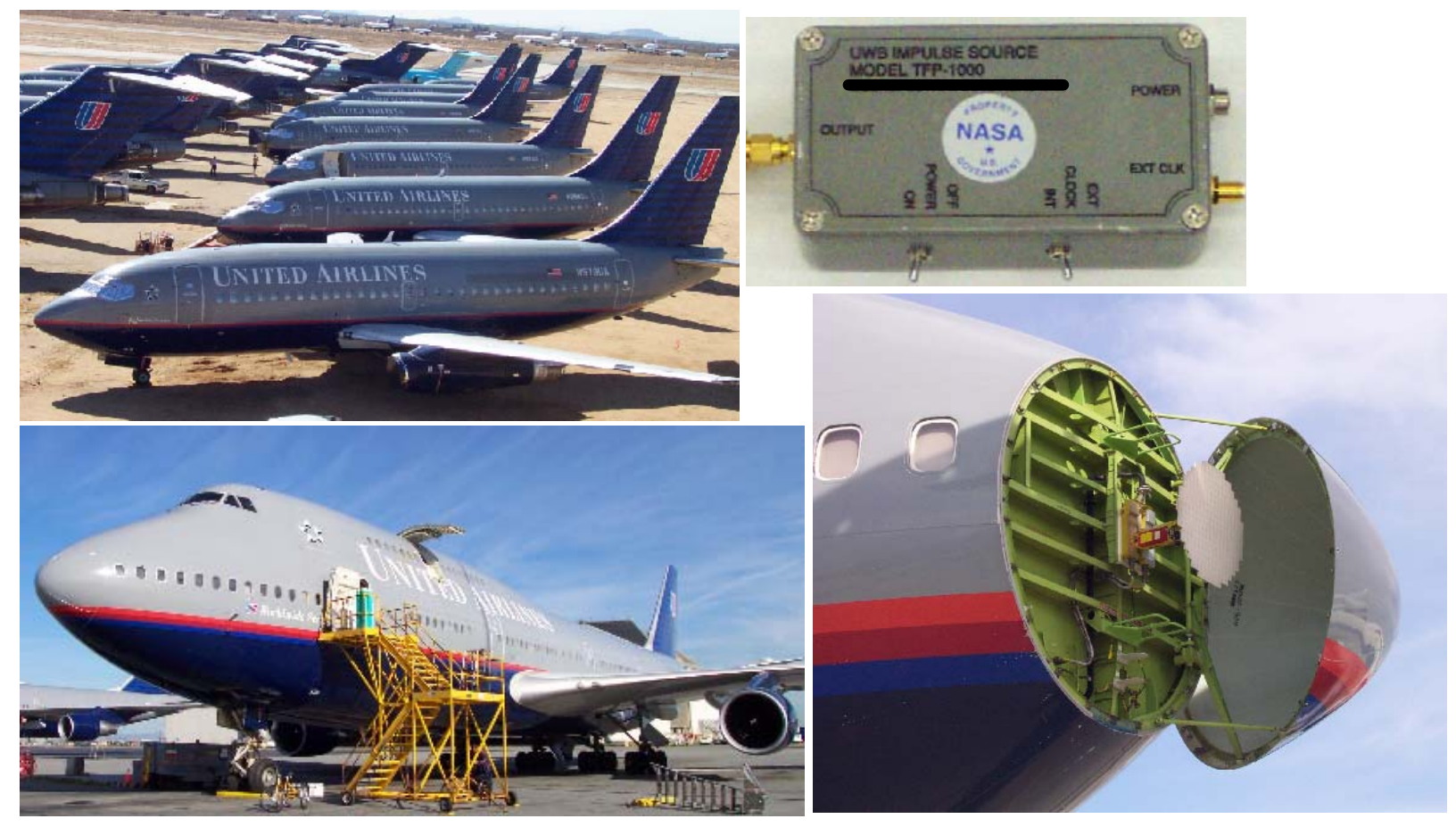

Figure 6: (a) Photograph of 6 B-737 airplanes used for IPL measurements. (b) Photograph of one of 4 B-747 airplanes used for IPL measurements. (c) UWB source used for EMI testing. (d) Photograph of ILS Localizer and Glideslope antennas inside a B-747 radome.

\section{Spurious Radiated Emission Measurements from T-PEDs}

In the Spring of 2001, NASA LaRC entered into an Interagency Agreement with the FAA and teamed with the University of Oklahoma Wireless EMC Center to develop a radiated emission measurement process for CDMA (IS95) and GSM (ETSI GSM 11.22) wireless phones. Spurious radiated emissions were characterized from devices tested in both semi-anechoic and reverberation chambers, in terms of effective isotropic radiated power. Eight representative handsets (4 GSM, 4 CDMA) were commanded to operate while varying their radio transmitter parameters (power, modulation, etc.). The NASA report ${ }^{28}$ provided a detailed description of the measurement process and resulting data, which may subsequently be used by others as a basis of consistent evaluation for cellular/PCS phones, Bluetooth, IEEE802.11b, IEEE802.11a, FRS/GMRS radios, and other portable transmitters. Aircraft interference path loss (IPL) and navigation radio interference threshold data from numerous reference documents, standards, and NASA partnerships were compiled. Using this data, a preliminary risk assessment was provided for CDMA and GSM wireless phone interference to aircraft localizer, Glideslope, VOR, and GPS radio receivers on typical transport airplanes. The report identified where existing data for device emissions, IPL, and navigation radio interference thresholds needs to be extended for an accurate risk assessment for wireless transmitters in aircraft. Some findings are listed here:

- None of the four CDMA and four GSM wireless handsets tested would individually be likely to interfere with aircraft VOR, LOC, GS, or GPS navigation radios.

- If a CDMA or GSM wireless handset radiated spurious signals equal to the maximum allowable FCC limits, it would result in large NEGATIVE safety margins, even when considering "reasonable minimum" radio receiver interference thresholds: 
- Each handset was commanded according to an extensive matrix of operational modes, while spurious radiated emissions were measured. CDMA handsets were commanded to multiple power output levels, puncture rate settings, and vocoder rate settings. GSM handsets were commanded to multiple power output levels, DTX and DRX, and speech CODEC settings. While the operating mode often resulted in discernable differences in the spurious radiated spectrum, dominant spectral components did not vary appreciably due to mode changes. Interestingly, repeatedly turning the handset power ON-OFF caused the most significant changes in the spurious radiated spectrum.

- It was demonstrated that intermittent spurious radiated emissions would sometimes increase up to $10 \mathrm{~dB}$ when touching the keypad, touching the antenna, or retracting the antenna on the test handsets. However, when compared to the highest emission levels in all operating modes, these manipulations resulted in only a 3-dB increase for the highest emission levels.

- It was demonstrated that GPS- and DME-band emissions occur, due to intermodulation between GSM and other wireless handset types, when the handsets were placed in close proximity to one another. It was identified that other combinations of common passenger transmitters could potentially produce intermodulation products in aircraft communication and navigation radio-frequency bands.

- It was identified that the FCC does not restrict airborne use of PCS wireless handsets. FCC limits for spurious radiated emissions for PCS handsets are the same as for cellular handsets. However, only cellular handsets are restricted from airborne operation by the FCC (47CFR22.925 [60]).

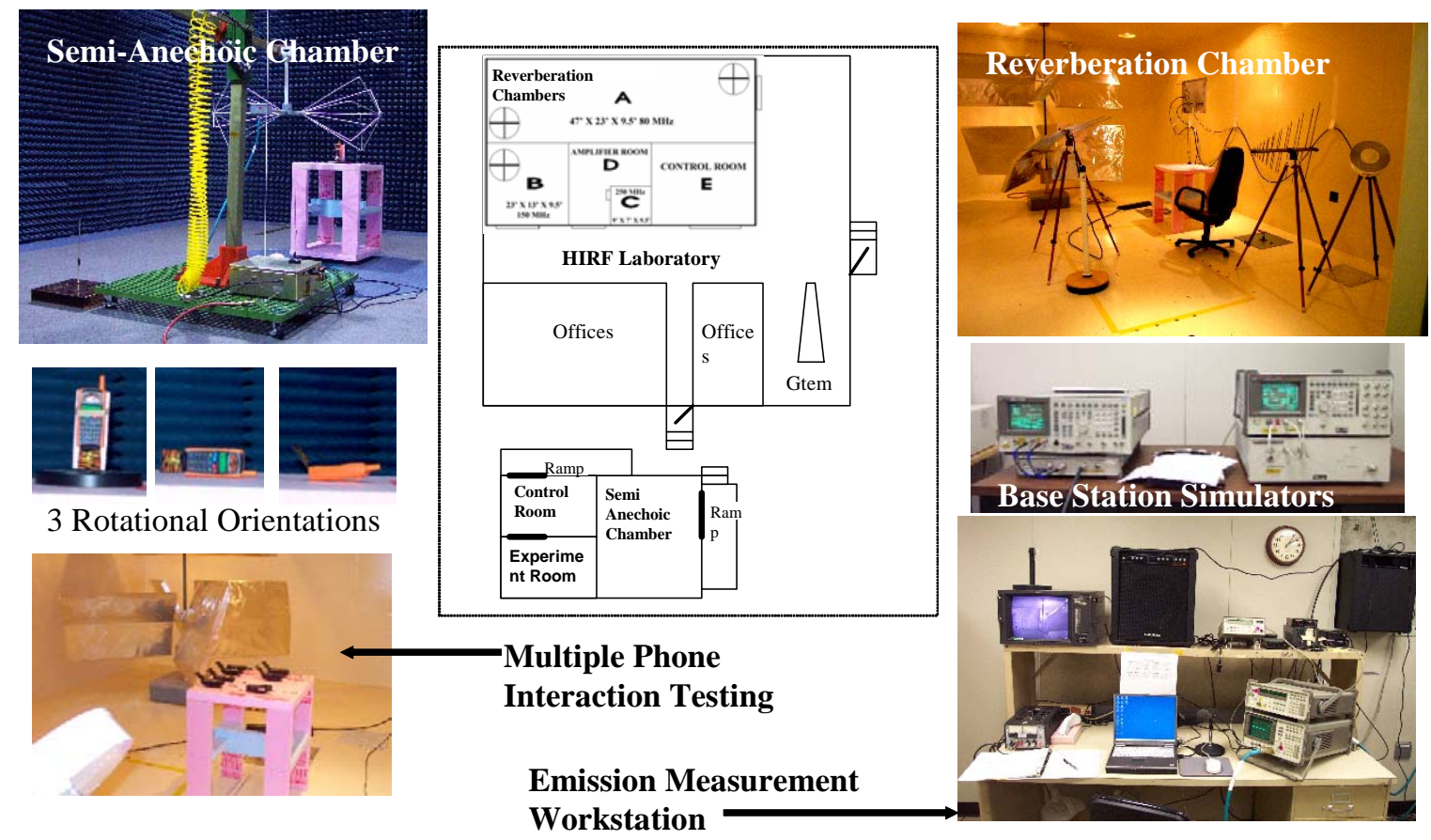

Figure 7: NASA Langley Research Center HIRF laboratory setups for measuring spurious radiated emissions from CDMA, GSM and other mobile phones and PEDs.

In 2003, the reverberation chamber measurement processes developed by NASA were extended to address Wireless Local Area Network devices and two-way radios, under a modification to the FAA/NASA Interagency Agreement. Spurious radiated emissions in aircraft radio frequency bands from several wireless network devices were compared with baseline emissions from standard computer laptops and personal digital assistants. In addition, spurious radiated emission data in aircraft radio frequency bands from seven pairs of two-way radios were provided. A description of the measurement process, device modes of operation and the measurement results were reported. A risk assessment was provided for interference from wireless network devices and two-way radios to aircraft systems, including Localizer, Glideslope, Very High Frequency Omnidirectional Range, Microwave Landing System and Global Positioning System. The report compared the interference risks associated with emissions from wireless 
network devices and two-way radios against standard laptops and personal digital assistants. Existing receiver interference threshold references are identified as to require more data for better interference risk assessments.

- It was determined that WLAN device spurious emissions are not any worse (not higher) than spurious emissions from computer laptops/PDAs in the VHF-Com band.

- The emission levels from WLAN devices and laptops/PDAs are lower than the FCC limits, but they can be higher than RTCA/DO-160D Category M limits.

- Spurious emissions in GS band from FRS and GMRS two-way radios can be $11 \mathrm{~dB}$ higher than RTCA/DO160D Category $\mathrm{M}$ limit, and $4 \mathrm{~dB}$ higher than the maximum laptop/PDA emissions in the same band.

- Interference threshold data are inadequate for thorough assessments the threat from PED-type EMI.

- Based on the limited interference threshold data, safety margin calculations were conducted. The results show that the safety margins can be negative or positive depending upon the interference thresholds value and the minimum IPL data (the lowest or the average) used.

802.11B
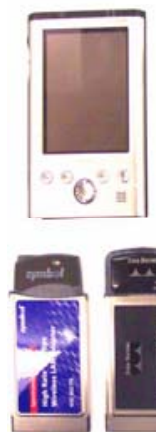

802.11A
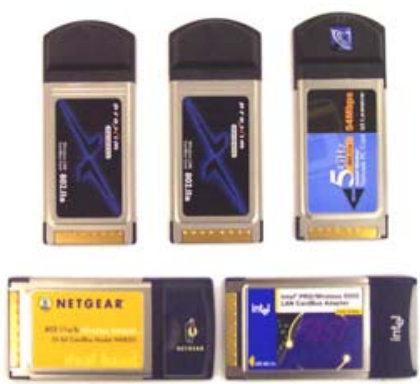

FRS Radios

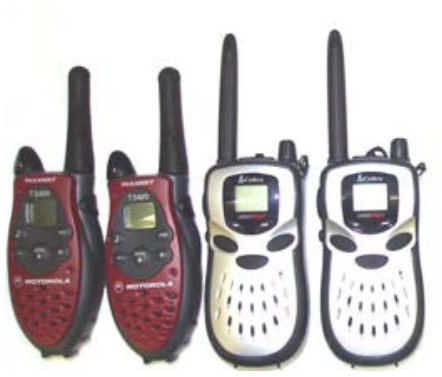

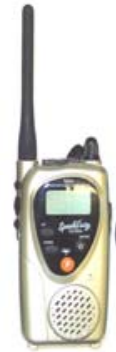

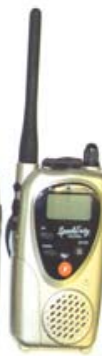

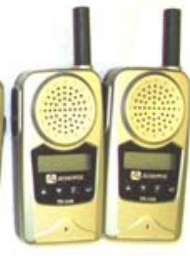

Bluetooth
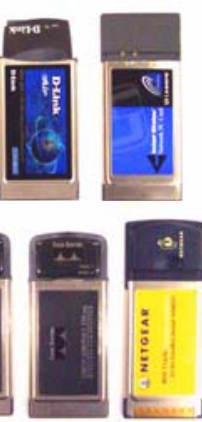

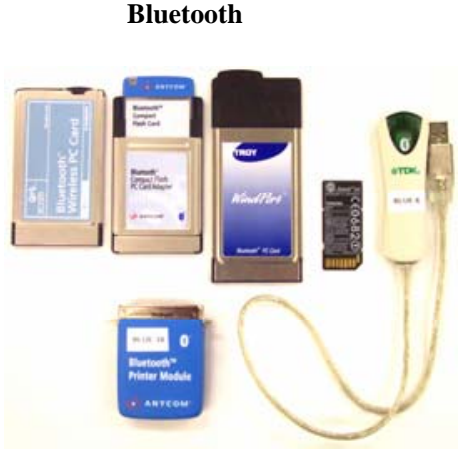

Figure 8: Wireless LAN \& PAN devices and FRS \& GMRS Radios measured for spurious radiated emissions

In 2004, NASA built upon the process and results from previous efforts, and evaluated newer generation mobile phones (again under a new modification to the FAA/NASA Interagency Agreement). Two of the latest and most popular technologies used in the US were the CDMA2000 1xRTT (1x Radio Transmission Technology) and the GSM/GPRS (General Packet Radio Service). In addition, phones operating in the higher frequency $1900 \mathrm{MHz}$ band were addressed. Emission measurements were conducted on 33 wireless phones of various design configurations by different manufacturers. These mobile phones were more representative of those available in today's market place than the mobile phones tested previously by NASA. Testing in both voice and data modes was conducted. The 
results were compared against baseline emissions from laptop computers and personal digital assistant devices that are currently allowed to operate on aircraft. The following observations were made:

- The 33 wireless phones tested did not generate higher emissions in most aircraft radio bands than standard laptop computers. An exception is the MLS band, where the emissions from the phone exceeded the emissions from the laptop computers. However, the safety margins in this band were positive for all devices.

- Spurious emissions from the wireless phones tested were below the aircraft installed equipment emission limits (RTCA/DO-160 Category M). They were also below the FCC Part 15 limits for unintentional transmitters such as laptop computers.

- The calculated safety margins can be negative or positive depending upon the interference thresholds (minimum or typical) and the minimum IPL data (the lowest or the average) used.

- It is generally observed that in lower frequency bands (VHF-Com, LOC, VOR and GS), each mobile phone's maximum emissions are similar regardless whether it is operating in the cellular or PCS bands. This is not the case for higher frequency bands (TCAS, DME, GPS or MLS).

- The measured emissions in the voice and data modes are generally similar for any single device (within 2-5 $\mathrm{dB}$ ) in most cases.

A new analysis of previously compiled and reported IPL summary data was used to provide a conservative bound for the multiple-equipment-factor (MEF). This factor is an estimate of the cumulative interference effects to aircraft radios if there are multiple similar devices present on the airplane. An approach was developed to provide an estimate of the upper bound on the front-door interference effects of multiple PEDs. This approach sums the interference powers at the receivers after scaling each device's emission by the IPL corresponding to its location. Using full-aircraft B737 IPL data, conservative upper bounds were derived for LOC, VHF and TCAS on a B737 airplane. The following observations were made:

- MEF determined using the windows-only IPL data were within one $\mathrm{dB}$ of the MEF determined using fullaircraft seat data.

- Conservative bounds for MEF for the systems measured were between $10 \mathrm{~dB}$ and $14 \mathrm{~dB}$ for LOC, VHFCom, VOR and GS.

- The effects of additional seats on the MEF calculation diminished rapidly with the increased distance between the seat locations and the windows/doors.

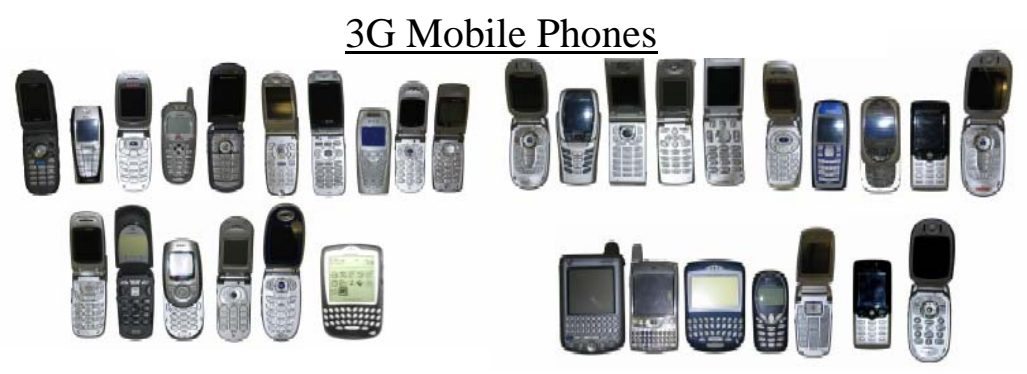

Figure 9: 3G mobile phones measured for spurious radiated emissions

In 2005, the FAA/NASA Interagency Agreement was again modified to develop a test methodology for assessing interference risk of active RFID devices to aircraft communication and navigation radios. RFID tags have been evaluated by air shipping companies, the U. S. Department of Defense and airlines to track luggage and to evaluate how well tags hold data and can be read when installed on nonrotating engine components. ${ }^{29}$ NASA purchased active tags and associated interrogators (ie. "readers", "signposts", etc.) from over five different manufacturers. A major challenge in this ongoing testing is to coordinate measurements of the spurious radiated emissions to when the tags are actually transmitting. The final report is expected in December 2005. 


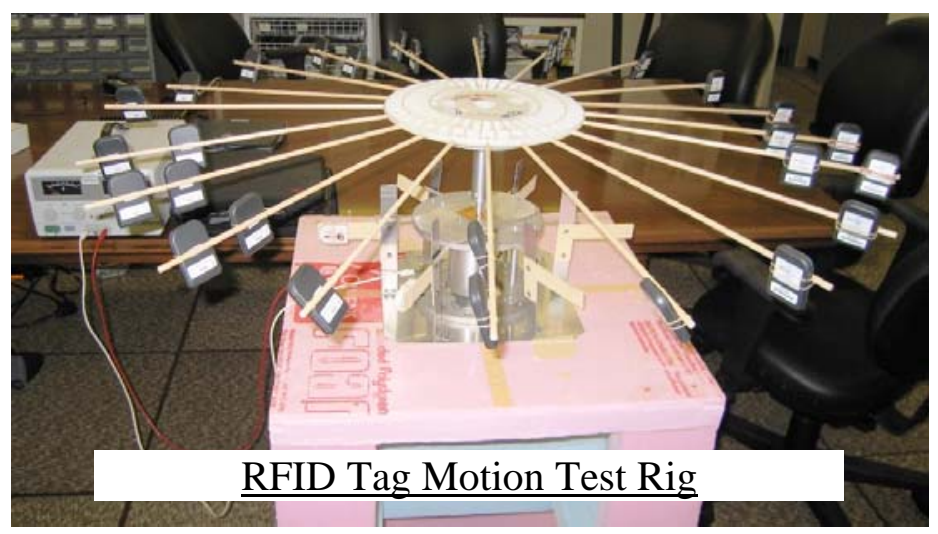

Some of NASA’s Typical Active RFID Tags

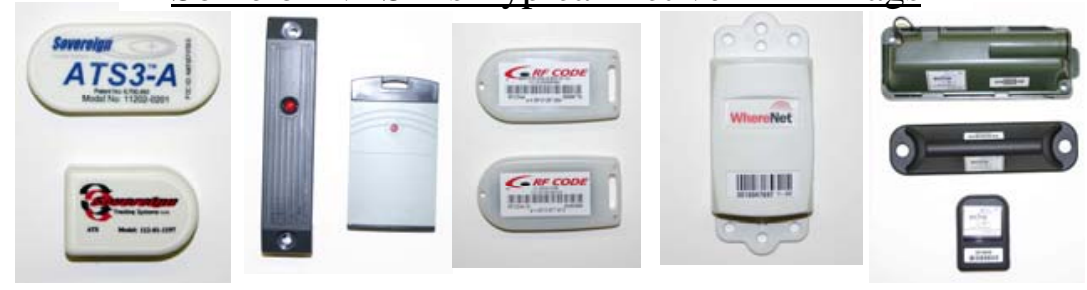

Figure 10: Assortment of active RFID tags and test rig for NASA spurious radiated emission measurements

\section{Direct Effect UWB Testing on Airplanes}

Ultrawideband (UWB) transmitters are one day expected to be integrated into a wide variety of portable electronic devices (PEDs) that passengers routinely carry on board commercial airplanes. The aeronautical community has been concerned as to whether evolving FCC UWB rules are adequate to protect legacy and emerging aeronautical radio systems from electromagnetic interference (EMI) from emerging UWB products. In a joint effort between NASA (Headquarters, Langley Research Center, Glenn Research Center, Ames Research Center), the FAA, United Airlines, EWI, Sky West Airlines and the U. S. Department of Transportation, specific UWB-type EMI signals were introduced to radio systems installed on airplanes, and to observe effects in the same context that they would appear to flight crews, in a realistic operational signal environment. Because all UWB threat signals were calibrated referenced to FCC 15.209 limits for unlicensed transmitters, this was the most extensive PED EMI direct effects testing ever performed on commercial airplanes. Extensive details regarding this work are reported in a NASA Technical Publication. ${ }^{30}$

Here is a brief summary of the test results:

- Aeronautical radio systems operating below $960 \mathrm{MHz}$ are at risk to EMI from handheld UWB consumer products meeting existing FCC requirements.

- Aeronautical radio systems operating above $960 \mathrm{MHz}$ were not affected by UWB emissions at levels meeting FCC UWB limits (15.519, handheld systems), when emitting from within airplane passenger cabins.

- UWB modulation cannot be assumed to reduce the likelihood of harmful interference.

- $\quad$ Numerous UWB PRF selections were shown to be effective at interfering with aircraft radios.

- UWB product effects upon onboard wireless systems remain unknown. (Such onboard systems would include cargo smoke detection, cabin communications and surveillance systems.)

Specific EMI effects observations are discussed in the next section. Aside from the test results, this study exposed several additional EMI-related safety and security concerns.

- Simultaneous EMI to multiple radio systems: EMI from a single PED can interfere with all parallel redundant aeronautical radio systems if they are tuned to the same radio channel. In addition, wide 
bandwidth EMI signals may cause interference to several different COM/NAV systems, operating on different channels, simultaneously. Thus, the redundancy designed to protect against component failure may not be effective in protecting against EMI.

- Hidden performance impairment due to EMI: COM/NAV system performance degradation effects can occur up to and including system failure on some aircraft systems without the flags, annunciations, or system status displays changing to indicate system failure of loss of capability.

- Interdependencies of aircraft communication, navigation \& surveillance (CNS) Systems: Some systems were observed to have their performance degraded by interference effects propagating from other systems.

- Non-standardized displays of navigation and flight information make it impossible to describe the airlinewide effects of EMI expected on particular COM/NAV systems from one aircraft type to another. The number, placement, size, and information content of COM/NAV system status and data displays are highly variable. Even the names of the primary displays and controls are not standardized among aircraft manufacturers or between aircraft types from some individual manufacturers.

- $\quad$ No crew procedure exists to identify, report, and resolve COM/NAV system EMI events that may be due to spurious (aeronautical radio frequency band) radiation from PEDs.

- $\quad$ The present aircraft certification process does not address vulnerability to EMI from PEDs.

- $\quad$ No specific detection devices are in place to alert the crew to the presence of EMI or degradation that may be occurring.

- The correlation between available test data (ground tests only) to actual flight conditions needs more study.

\section{Evidence of EMI: What EMI Effects May Look Like To a Flight Crew}

The study of UWB direct effects on COM/NAV systems provided a unique opportunity for observing anomalous aircraft system behavior that may result from EMI. In order to manage the operational impact of EMI effects, it is first necessary to describe them from a pilot's viewpoint. A general description of EMI effects for several $\mathrm{COM} / \mathrm{NAV}$ systems observed during the UWB test project is provided here, and operational methods to handle these effects are explored.

The effects on VHF-COM varied with specific EMI signal modulation types, as well as the particular model of aircraft radio. Some VHF radios went suddenly silent without any indication of interference prior to reaching the upset threshold or any alerting to the crew. Other VHF radios experienced audible distortion and unwanted noise as the interfering signal power level increased, until some point at which voice communication was judged to be unusable by the pilot. No specific failure flags, indications or audible/visual warnings occurred during EMI testing for VHF Com. VHF radio failure effects occurred in a similar manner and at a similar level when the EMI signal was transmitted from numerous locations over much of the passenger cabin. Thus for situations where unwanted noise due to EMI is occurring, crew selection of an alternate VHF COM system would not likely mitigate the effect, but would provide confidence that the effect is being caused by EMI rather than system failure.

For VOR and ILS (Localizer and Glideslope), visible variations in both vertical and horizontal indicators were observed to be caused by the EMI signal. The variations were of two types: offsets from the course or glideslope and/or fluctuations. Both effects ranged from tenths of a mark (diamonds, dots, or lines) to 2 marks. "Operational EMI Failure" was declared upon blanking (or stowing) of the indicator needles on the navigation displays. This may or may not have been indicated by a failure flag, and may have appeared as though the reference signal was too weak to be received (i.e. out of range). "System EMI Failure" was indicated by a VOR, Localizer or Glideslope failure flag appearing on a navigation display. Due to EMI source path loss differences, effects were generally more severe on one particular aircraft system versus redundant systems, therefore, crew operational procedures that include checking redundant system data may be helpful for mitigating EMI impact. The audio (Morse-code) identifiers were sometimes affected first, sometimes simultaneously with the visual effects, and sometimes not at all. Therefore the audio identifiers provided no sure indication of whether the indicated direction was disturbed.

The most common EMI effect on DME was blanking of the displayed DME data. Due to EMI source path loss differences, effects were generally more severe on one particular aircraft system versus redundant systems, therefore, crew operational procedures that include checking redundant system data may be helpful for mitigating EMI impact. On some systems, using live DME signals, the indicated distance to that site varied up to 1 nautical mile when an EMI signal was present. The audio (Morse-code) identifiers were sometimes affected first, sometimes simultaneously with the displayed effects, and sometimes not at all. Therefore the audio identifiers provided no sure indication of whether the indicated direction was disturbed. Occasionally, the "ATC Fail" light illuminated during 
DME EMI tests. No specific failure flags, indications or audible/visual warnings occurred during UWB EMI testing for DME, other than the loss of DME data.

For the ATC Transponder, EMI effects were not observable by the crew up to and beyond the point of an "ATC FAIL" indication. The best results were obtained when monitoring ATC reply efficiency using a ramp test set. Operational EMI Failure was defined as a drop below $90 \%$ in aircraft replies to interrogations.

In some cases, distant TCAS airplane images disappeared off the crew display due to interfering signals. On some systems the TCAS fail light and/or the ATC fail light preceded the loss of airplane images. On some systems the fail lights did not illuminate with any event. On some aircraft, the only indication of an ATC failure was that the red "reply" light stopped blinking. From these observations, it may be beneficial for crew operational procedures to include checks of the ATC reply indicator if PED EMI is suspected. Failures took seconds to minutes after illumination by PED emissions to occur and seconds to minutes to recover after removal of the interfering signal. EMI effects to ATC and TCAS receivers gradually increased with higher EMI signal power levels. Thus, PED EMI is more likely to affect system processing of TCAS interrogations and ATC replies from distant airplanes rather than nearby airplanes.

For GPS, the type and extent of system status data varied greatly from aircraft to aircraft. Most aircraft GPS user interfaces simply provided "No Computed Data", or "System Fail” warnings, and number of satellites tracked. Less commonly, some airplane GPS displays included signal health information about each satellite in view. Flight operational procedures should include training about how GPS data is used by the aircraft systems and how to determine degradation of GPS signal reception. For one airplane system, it was observed that increasing the EMI power level caused the GPS system to shift into reduced capability modes, thereby providing less information (no altitude) and poorer fix accuracy. On one airplane, EMI resulted in aural commands to "pull up" emanating from the ground proximity warning annunciator. Presumably, this may have been caused by loss of GPS position accuracy, however it is uncertain whether a pilot encountering such a warning would consider the cause to be PED EMI. Secondary effects to autopilot, flight director, flight management system, etc. caused by loss of COM/NAV data are not considered in these descriptions. The reaction of pilots to the aural and visual symptoms of EMI interference seen in the tests is likely to vary widely by aircraft type, COM/NAV system type, phase of flight, flight conditions, pilot technical knowledge of the system, and pilot flying experience. One of the reasons offered for why many pilots have never seen significant EMI effects is that the probability of channel and time coincidence between PED interference and specific COM/NAV systems channel usage today is very low. This may not be the case as UWB and other emerging PED radio technologies become ubiquitous.

Operational availability of the SATCOM system was not readily apparent to the crew. SATCOM output is used as a part of the automated radio system. It was possible for the on-board PED system to keep the satellite system searching indefinitely for a clear channel with the PED system transmitting from inside the passenger cabin. Therefore it would be helpful for crew operational procedures to include periodic checks on SATCOM status.

\section{EMI Detection and Mitigation for Aviation Safety and Security.}

\section{A. EMI: Inadvertent or Malicious?}

Until recently, it was generally assumed that EMI situations that occur on commercial airplanes would be caused unintentionally. Today's increased awareness of global terrorism, and the expanding media coverage of EMI weapons, makes it more likely that EMI weapons may be used against airplanes and CNS/ATM infrastructure in the future. Figure 4 shows a sampling of magazine coverage of this threat.

On February 25, 1998, the U. S. Congress held a Joint Economic Committee Hearing on Radio Frequency Weapons and Proliferation. In one of the recorded statements, Dr. R. Alan Kehs of the Army Research Lab asked a profound question: "At what point do common civilian electronic devices become weapons?"31 

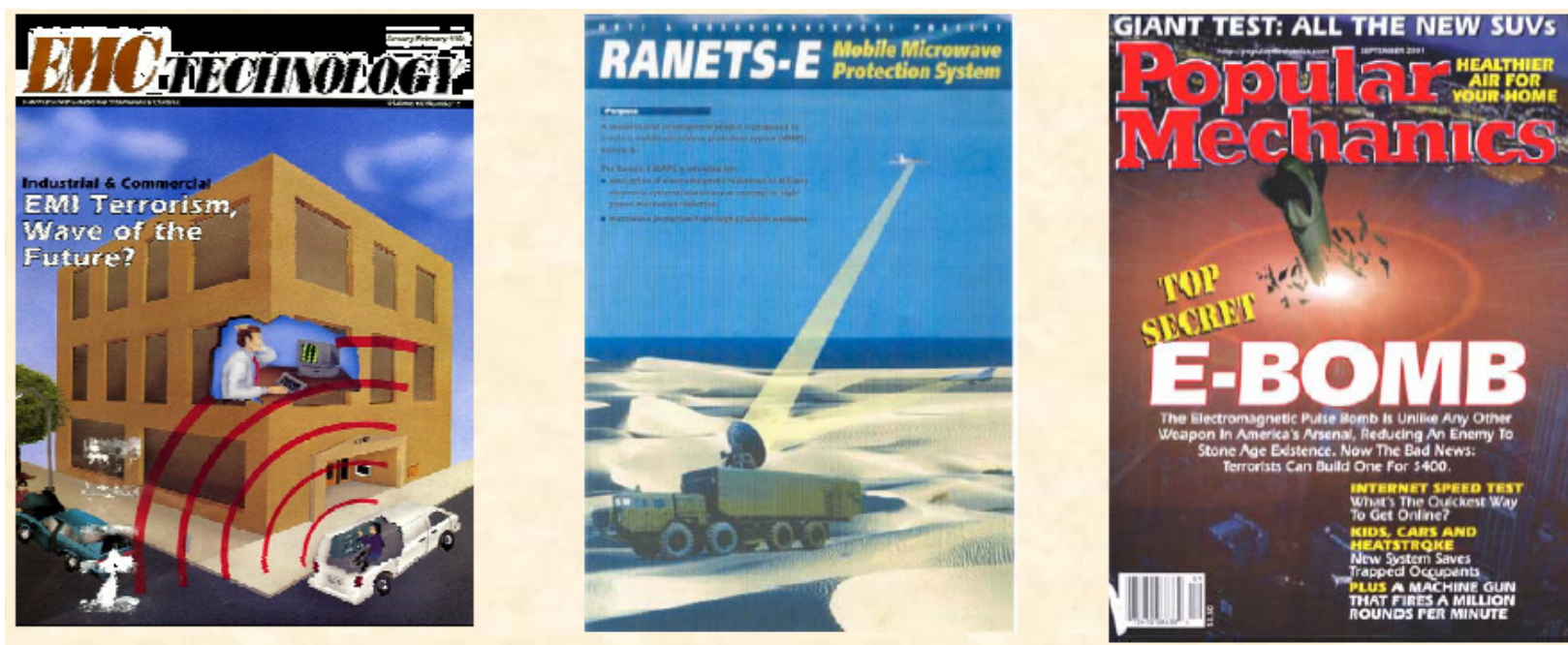

Figure 11: Sample of Magazine coverage of EMI Weapons and Terrorism

\section{B. EMI Detection}

In August 1996, RTCA Special Committee-177 recommended "Government and industry should pursue research into the design and feasibility of using devices designed to detect emissions that produce electromagnetic interference from PEDs within aircraft cabins". Soon after publication of the RTCA/DO-233 report, the FAA entered into a Small Business Innovative Research (SBIR) contract with Megawave Corporation (Boylston, Massachusetts) and Embry Riddle Aeronautical University (ERAU, Daytona Beach, Florida) to design a system for the detection and localization of potentially harmful radiation from PEDs carried onboard aircraft. The system was designed to monitor the radio spectrum from 50 to $2000 \mathrm{MHz}$, with up to 64 sensors distributed throughout the passenger cabin of an airplane. Unfortunately, funding and sponsorship of the system dissolved before a prototype could be built. To date, the Megawave/ERAU design remains the most comprehensive approach for a PED detection system. Details of the design were presented at the 1998 Digital Avionics Systems Conference ${ }^{32}$. Aside from a system designed exclusively for installation on aircraft, other PED detection options have become available since the RTCA/DO-233 recommendation. Holaday Industries (now a part of ETS-Lindgren) markets a Cell Alert system for detection and alerting of wireless phones that may be activated in the hospital environment, but are unauthorized. Details may be found at http://www.emctest.com/Holaday/pa3.htm. Cellbusters.com, in Phoenix, Arizona, manufactures the Cellbuster ${ }^{\circledR}$, which appears similar to the Cell Alert ${ }^{\circledR}$, and is marketed for use in power plants, airports, medical clinics, computer rooms, transportation operations, industrial plants, control rooms, laboratories, financial institutions, courthouses, government buildings, legal offices, embassies, and defense facilities. Details may be found at http://www.cellbusters.com. Channel Business Services, of Hamburg Germany, markets the Mobifinder ${ }^{\circledR}$ mobile phone detector, for use in airplanes, airports, hospitals, doctor’s offices, medical laboratories, near fuel depots and gas stations, and other security areas. Further details may be found at http://www.mobifinder.de/english/products/index.html. Alitalia Airlines has evaluated the Mobifinder ${ }^{\circledR}$ as a tool for the chief cabin attendant on some flights in $1998^{33}$, and found that it was often difficult to identify the exact location of the unauthorized transmitter. The Alitalia evaluation team recommended that multiple Mobifinder ${ }^{\circledR}$ units be used to increase the likelihood of threat localization, to heighten passenger awareness to the potential hazards of wireless phones, and to aid the flight crews in resolving suspected EMI events. Other PED detection products are also likely to be (or become) available. Narda East (L3 Communications), in Hauppauge, New York has advertised the portable AirGuard ${ }^{\circledR}$ PED sensor, for detecting PED emissions that may be present in aircraft communication/navigation frequency bands, and has demonstrated a prototype unit at NASA LaRC. The Narda approach is subtly different from the other approaches because it focuses on excessive PED emissions in aircraft frequency bands, rather than detecting specific T-PED frequencies that have been designated as unauthorized for use 
onboard airplanes. This significant difference was identified in the Megawave/ERAU study, and acknowledged to be of significant design concern for an operational system to provide a high probability of detecting potentially harmful PED signals, while not burdening flight crews with false alarms. The most difficult issues relating to the detection of unauthorized PEDs are less technical than financial and operational. Any piece of electronic equipment an airline designates for use onboard their aircraft must be certified for flight worthiness according to FAA regulations. Certification may add significant cost over the base price of the equipment. Also, airplanes can only generate revenue when they are carrying passengers. Thus, an installed PED detection system is subject to the additional cost of lost revenues during its installation time. Once the technical issues and certification requirements for a PED detection system have been resolved, flight crew training and enforcement policies must be developed to address situations when potentially harmful PEDs are being used by passengers.

More recently several mobile phone manufacturers have demonstrated picocell systems to RTCA SC-202 and EUROCAE WG-58 that could be considered to be mobile phone detection and mitigation systems. Such systems have the benefit of being able to command the participating handsets to transmit at minimum power, thus possible reducing EMI risk. Unfortunately, regulatory guidelines make it difficult to design such a system that will work with all the mobile phone technologies used by passengers on a typical airplane flight (ie. CDMA, GSM, PCS, PDC, 3G, EDGE, etc.). In addition, it is nearly impossible to ensure that passenger mobile phones will not bypass the onboard picocell and transmit (at maximum power output) to a terrestrial base station below.

One day, it is likely that some form of EMI detector will be commonly installed on board commercial airliners. A simple cockpit indicator for one such concept is pictured in Figure 12. Detected signals that are not authorized for the current flight phase, or violate airline policy, would be annunciated with a display in the yellow "Alert" range. Detected signals that are likely to exceed allowable limits for safe operation of the aircraft would be annunciated with a display in the red ("Alarm") range. Additional information, such as the possible location of the offending EMI source an a suggested course of action could be displayed in the "Message" field.

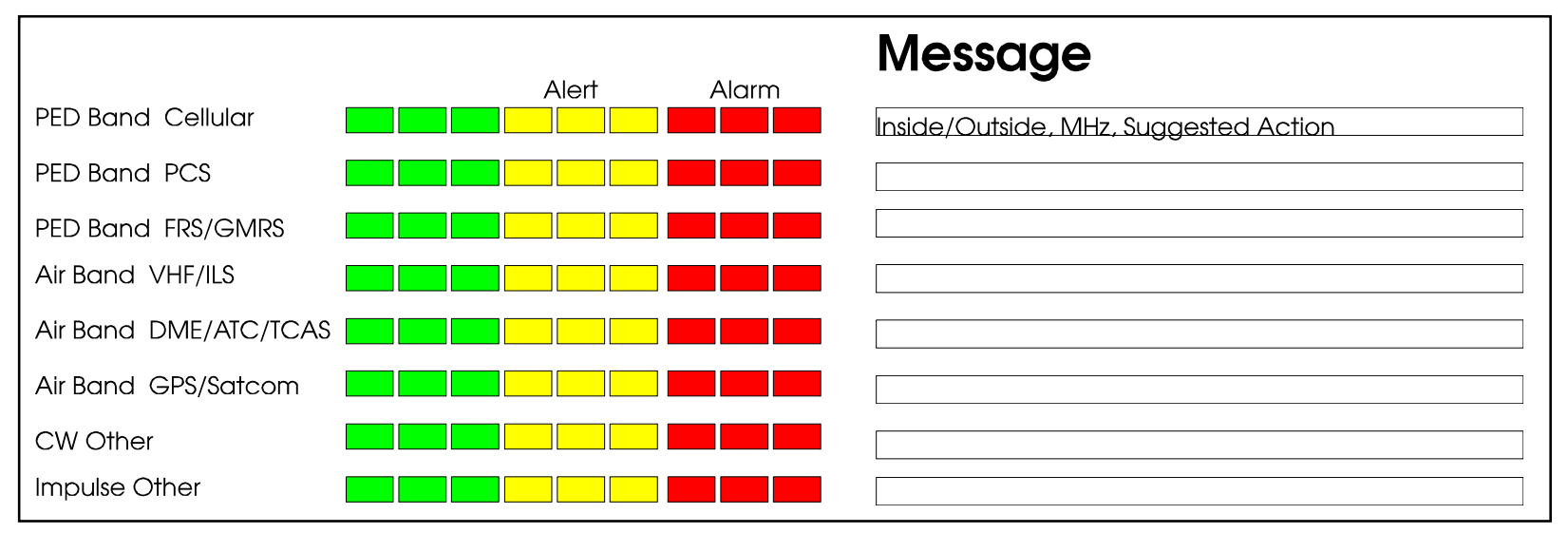

Figure 12: RF threat indicator (or status page on multifunction display)

\section{EMI Shielding Evaluation}

The first reported measurements of electromagnetic shielding of commercial airplane apertures to prevent PED coupling to aircraft radio systems was performed by Veda Incorporated, under contract to the FAA. ${ }^{34}$ A median shielding effectiveness of 26 to $35 \mathrm{~dB}$ was reported when covering all port and starboard windows with aluminum foil and tape. It was observed that shielding all the windows resulted in more variation of field levels inside the passenger cabin (ie. "stronger modal structure"). Veda also experimented with using 2-inch foil tape to partially cover aircraft windows. Over $10 \mathrm{~dB}$ of additional shielding was reported when using only one strip of 2-inch tape. Various combinations of aluminum tape and alternating window coverage were examined. The report did not reveal the dependency of shielding effectiveness on particular RF bands however. 
Additional shielding measurements were performed by NASA, EWI and United Airlines on B737-200 aircraft at Victorville, CA in $2002^{35}$. The merit of PED EMI mitigation by conductive sealing of door and exit seams was evaluated by measuring airplane IPL with (and without) aluminum foil bonded along all window and door exit seams along both sides of the airplane. See Figure 13, right. IPL measurement comparisons were performed for the VHF1 communications, LOC and GPS aeronautical radio systems. Coupling from all passenger cabin window locations to the VHF1 aeronautical communication system was reduced by about $5 \mathrm{~dB}$, and an even greater benefit, up to $15 \mathrm{~dB}$, was obtained at the door and window exit locations when the seams were conductively sealed. For LOC, coupling at most window locations was not significantly reduced. More than $10 \mathrm{~dB}$ of coupling reduction was obtained at the doorways when the seams were conductively sealed. The merit of PED EMI mitigation by the application of conductive window film was evaluated by measuring airplane IPL with (and without) film installed on the first 12 windows on the starboard side of the airplane. See Figure 13, left. It was shown that coupling levels may be reduced by more than $15 \mathrm{~dB}$ for GPS and more than $10 \mathrm{~dB}$ for TCAS by application of conductive window film. These results demonstrate that the application of conductive films to aircraft windows may provide significant reduction in PED EMI coupling to aircraft radio systems. This testing did not evaluate the level of protection possible to aeronautical radio systems operating in the VHF and UHF radio frequency bands (ie. VHF Com, VHF Omniranging, LOC, Glideslope) by applying conductive window film. It was recommended that more comprehensive evaluations of conductive sealing of door seams combined with conductive window films be performed for all aircraft radio systems in the future. These tests should consider aging issues and maintenance strategies in the selection of materials and their installation.

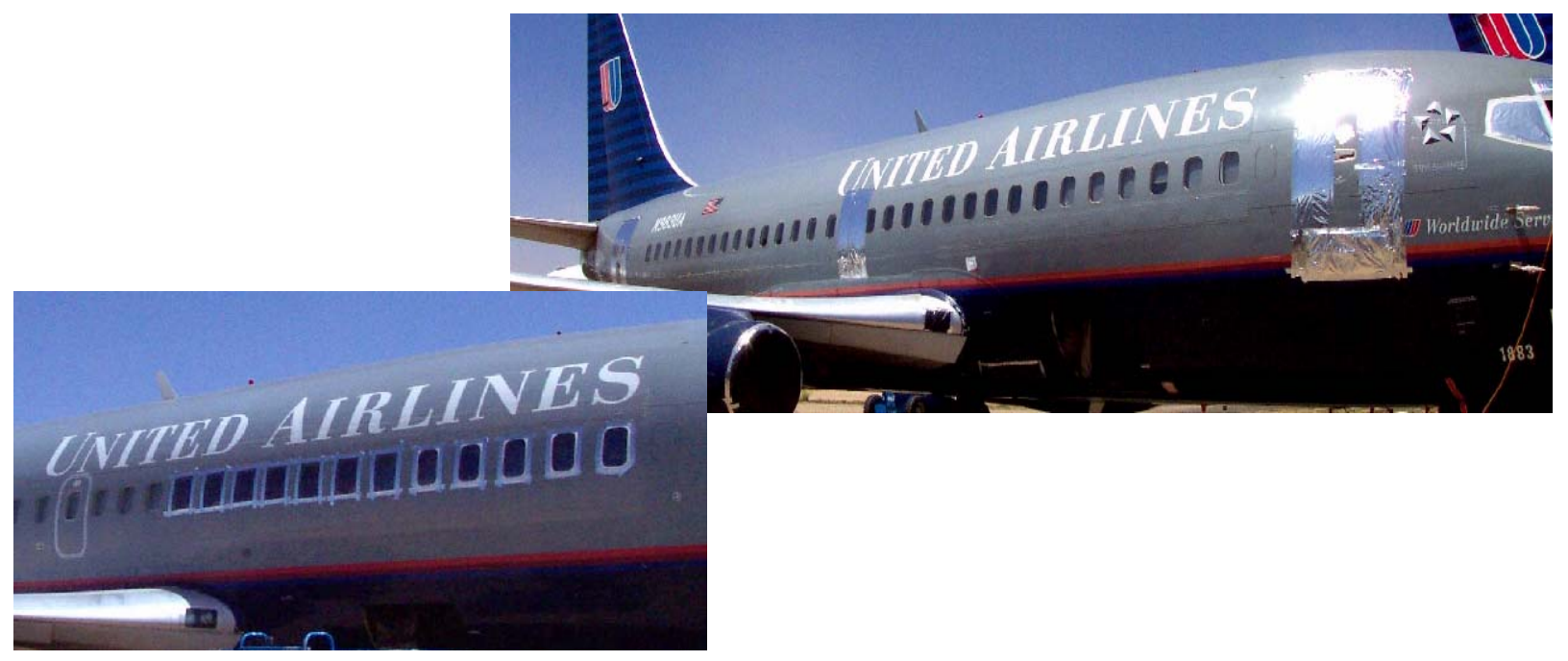

Figure 13: Top: Photo of airplane with door and exit seams electrically sealed with aluminum foil and tape. Bottom: Photo of airplane with the first 12 window apertures electrically sealed with transparent conductive film.

During the course of some inspections of different types of aircraft doors, it was notices that B-777 doors appear to be designed for improved electrical bonding to the aircraft structure. A photograph showing the change is shown in Figure 5. Previous measurements by EWI and Delta airlines indicate that this change aircraft door seal design may increase PED path loss through aircraft doors. 

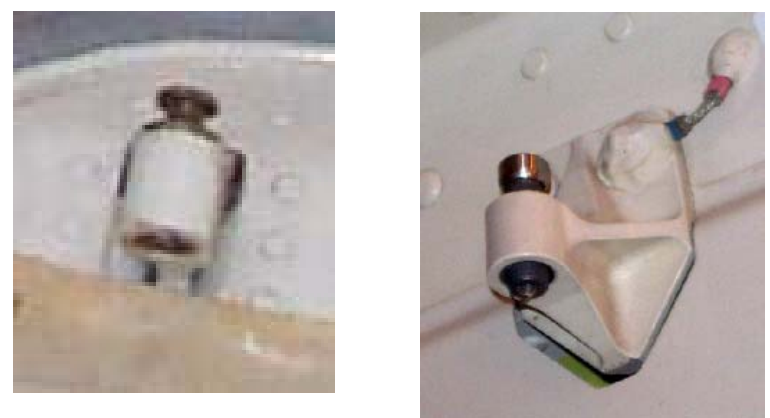

Figure 14: Left: B747-400 Door contact point. Right: B777 door contact point. Note: each contact point on the B777 door has a ground strap.

The Aerospace Vehicle Systems Institute, part of Texas A\&M University, currently has a project entitled "Mitigating the impact of RF Emissions from PEDS Through Aircraft hardening". The work is being performed under an industry partnership, and is expected to provide valuable insight to RTCA SC-202.

\section{A. Within the Next Decade}

\section{The Future}

We are clearly in the midst of an unprecedented age of personal connectivity. Given the widespread adoption of multi-band (and international band) mobile phones, wireless LANs \& PAN enabled PDA's, and keyless entry systems, it is not unusual for a typical person to be carrying several transmitting devices at one time. The introduction of UWB devices and RFID systems will surely lead to devices that are "location aware" within the next several years. With improved authentication, encryption and security protocols, people will become increasingly comfortable using their devices for purchases and exchange of personal information. It will soon become more difficult for many people to even know that they are carrying transmitters. In fact, it is possible that many people will become reluctant to turn their devices off at any time.

Several updated aeronautical radio services have been introduced over the past 10 years. Existing aeronautical VHF Com infrastructure has been updated with VHF Datalink (VDL) capability, that allows digital controller-pilot datalink (CPDLC) of text information, Wide Area Augmentation (WAAS) differential corrections of GPS navigation data), and airplane broadcast of position and altitude information (Automatic Dependent Surveillance Broadcast, ADS-B. ADS-B has been tested using aircraft universal access transceivers (UAT), SATCOM, and by placing extended spectral content onto aircraft radio transponders. Many more details may be found in the FAA's Operational Evolution Plan (OEP). ${ }^{36}$

Perhaps one of the most exciting opportunities for the near future is the Airborne Internet. The idea of an Airborne Internet began as a supporting technology for NASA's Small Aircraft Transportation System (SATS). ${ }^{37}$ The ultimate goal is to establish a robust communications channel between aircraft and various ground networks. United Airlines has joined with AeroSat, Inc. (http://www.aerosat.com), Computer Networks \& Software, Inc. (http://www.cnsw.com), Project Management Enterprises, Inc. (http://www.pmei.com) and Mulkerin Associates, Inc. (http://www.mulkerin.com) to form the Airborne Internet Consortium (http://www.airborneinternet.org/) The Airborne Internet Consortium promises to make aircraft easier to fly with more situational awareness, safety, and security, by utilizing Internet protocols and services in flight. These new services will also increase the productivity of passengers because the growth in connectivity will allow people in transit to use otherwise unproductive time.

This expanding use of RF spectrum for personal connectivity, combined with new and unforeseen applications of Airborne Internet and expanding aeronautical radio services makes it likely that more EMI interactions will occur. Figure 15 shows an overview of PED and CNS technologies of today and tomorrow. The middle area identifies the level of published data addressing their potential interactions. Though the efforts of the RTCA, FAA, NASA, airlines, avionics manufacturers, aircraft manufacturers and others, significant information is available to assess the 
potential interaction between today's PEDs and today's CNS systems. Much work remains to ensure that these exciting new applications do not lead to unforeseen consequences.

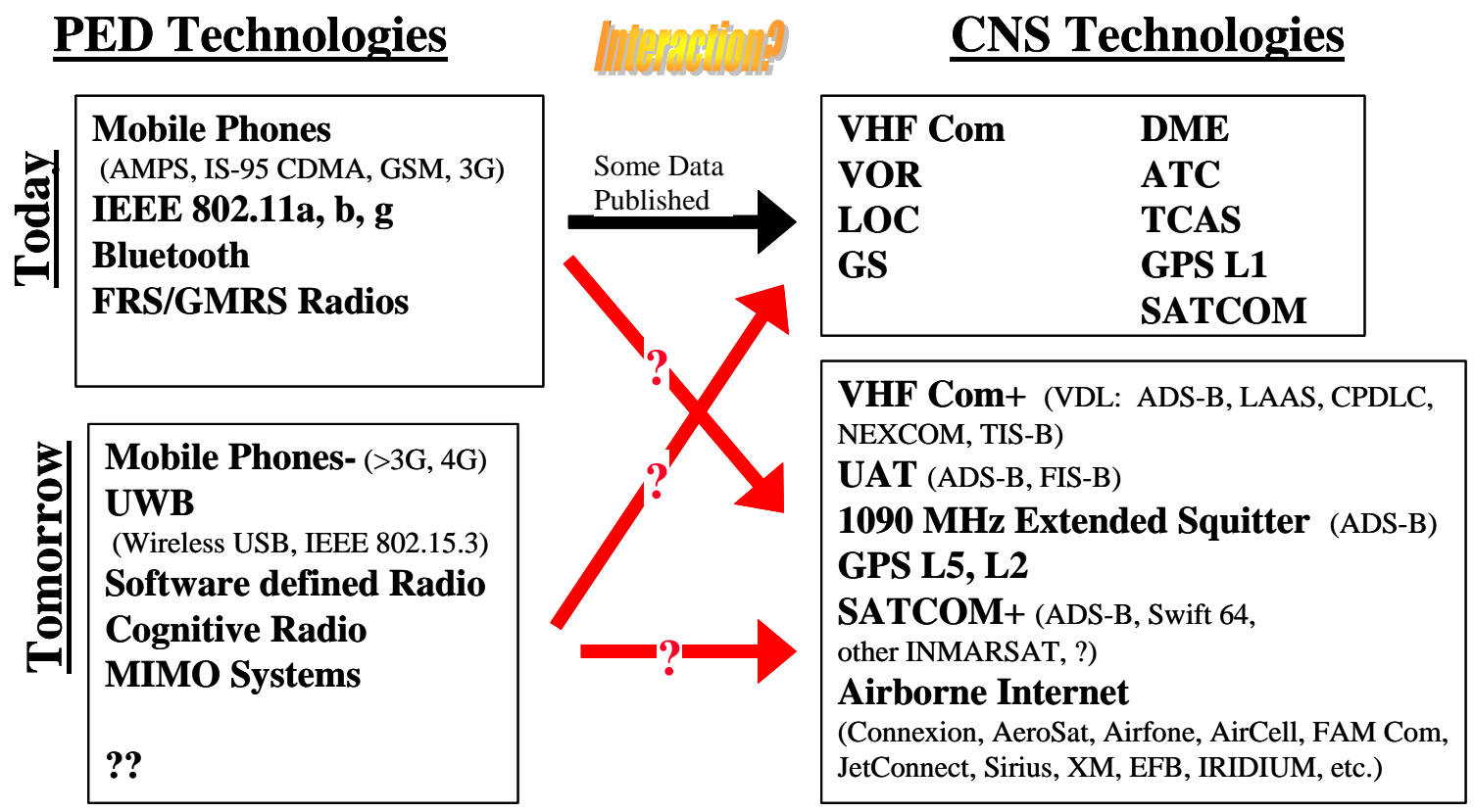

Figure 15: Overview of PED and CNS technologies of today and tomorrow, showing the level of published data addressing their potential interactions.

\section{B. Within the Next Few Decades}

With the increasing demand for more and more wireless bandwidth, RF spectrum will become increasingly scarce. In the near term, this is already leading to more efficient waveform technologies being used in existing RF spectrum allocations (ie. closer channel spacing, spread spectrum technologies, frequency reuse, etc.). Today, software defined radio (SDR) systems are being evaluated that can operate bandwidths of hundreds of Megahertz. Current research utilizing channel sensing, broadband monitoring, adaptive transmit power and adaptive bandwidth will lead to systems that can readily adapt to their RF environment. Furthermore, as technology progresses to allow radio systems to become aware of their location (ie. RFID, GPS, etc.), it will become possible for future T-PEDs to adjust their frequency use and power levels to conform to local and international RF spectrum restrictions.

An overview of this expected transformation was published in the January 2005 Joint E3 Bulletin. ${ }^{38}$ In the Bulletin, it is stated that "a fundamental transformation is required in the way the DoD obtains and utilizes its spectrum resources if it is to effectively employ emerging technologies such as smart antennas, ultra-wideband (UWB) systems, software-defined radios (SDRs), and adaptive waveforms.” To support this transformation, the DOD has established the Emerging Spectrum Technologies (EST) Program to examine how spectrum is accessed and utilized by the DoD in the future. An excellent chart from this reference is provided in Figure 16. 


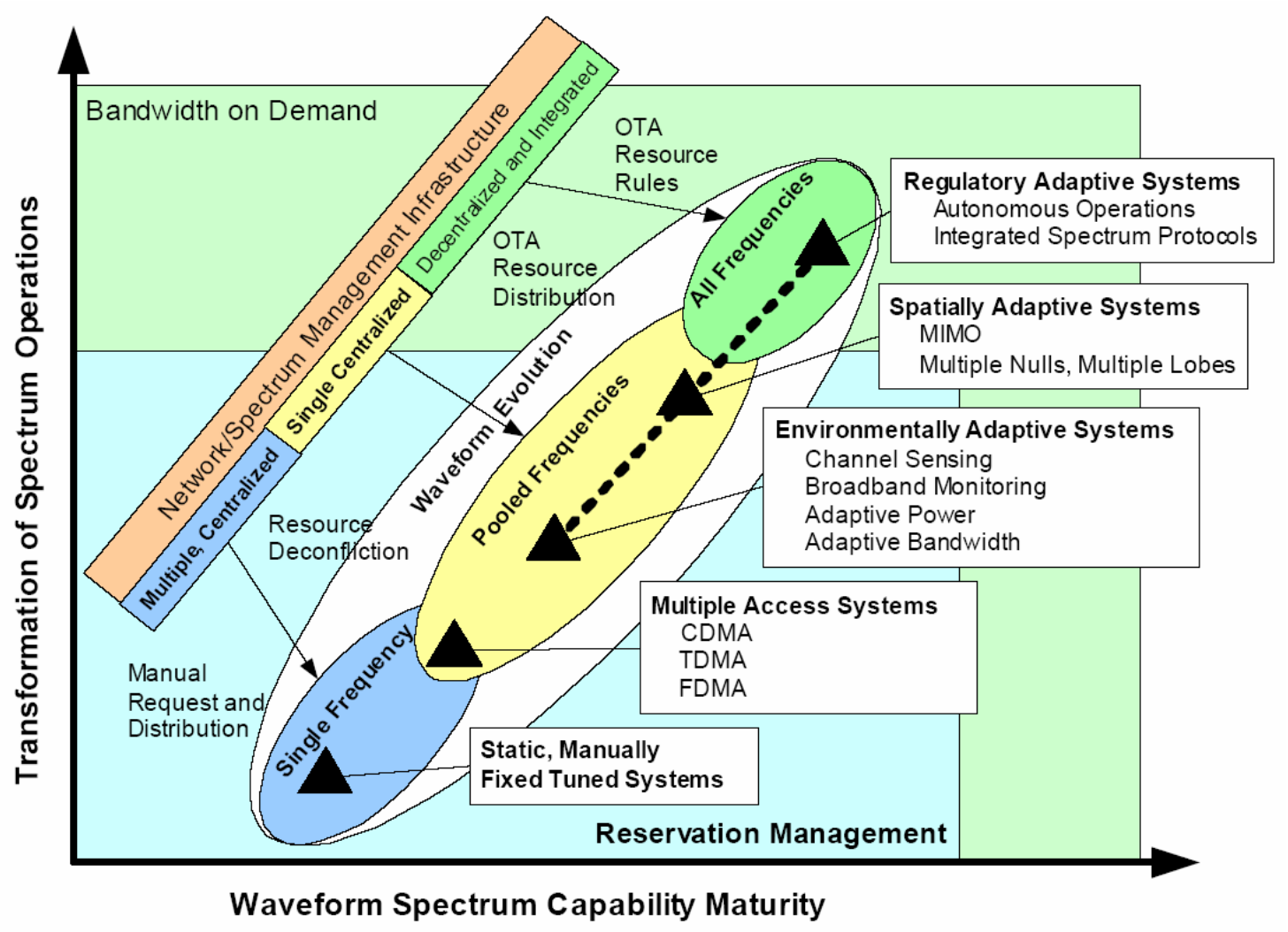

Figure 16: U. S. Department of Defense perspective on the transformation of RF spectrum operations

\section{Conclusions and Recommendations}

Aeronautical CNS, ATM and IFE are in the midst of a transformational era. Surely, broad bandwidth, low cost datalinks will find their way onto passenger airplanes. Air carriers, passengers and governments will find creative and ingenious ways to utilize these technologies to improve the safety, economy, efficiency and enjoyment of air travel. We are also in the midst of an exciting age of personal wireless connectivity. As air travelers continue to become more comfortable with existing and emerging wireless transmitters, it will becoming increasingly difficult for flight attendants and passengers to discern whether today's highly integrated and multi-function devices are designed to transmit or not. Observations suggest that passengers are increasingly likely to knowingly operate unauthorized transmitters while on board aircraft.

The interplay between evolving CNS, ATM, IFE, and passenger wireless connectivity will continue to evolve in ways that will certainly impact the safety and security of air travel. It will be a continuing challenge to understand safety and security problems as/before they develop, design solutions to those problems, and effect policy and procedural changes for airlines and governments.

\section{A. Understanding the Problem}

\section{PED Spurious Radiated Emissions}

Through the efforts of RTCA committees, NASA, the FAA and others, a significant body of PED spurious radiated emission data has been published. A standard set of procedures for measuring spurious radiated emissions in aircraft navigation radio-frequency bands from common and emerging wireless transmitters has been developed. While these efforts quantify the threat from many existing PEDs, they do not bound the potential EMI threat from newly emerging T-PEDs, or modified or damaged devices. Radiated emission characteristics of future T-PEDs will 
also need to be determined. In fact, new radiated emission measurement processes should be expanded to account for signal characteristics other than peak amplitude (i.e., modulation types and parameters, duty cycle, bandwidth, etc.), for more accurately quantifying the potential for EMI to aircraft communication and navigation radios. It may be possible to build database to establish confidence in signal compatibility for certain product types, and identify particular products that threaten aircraft signals. Finally, it is important to study the potential for devices transmitting on different frequencies, and possibly regulated by different national standards, to generate intermodulation products in aircraft navigation radio-frequency bands. While FCC and CISPR emissions standards must be met for products sold in the United States and Europe, they are not intended, and are therefore inadequate, for protecting aircraft spectrum from passenger generated EMI.

\section{Aircraft Coupling Data}

Extensive front-door IPL data has been collected by the RTCA, NASA, EWI, Delta Airlines, United Airlines, Sky West Airlines, Air Wisconsin, Airbus and others. Unfortunately, all this data is not compiled in a standard format in a single comprehensive reference. Many airplane types have never been subject to such measurements. Also, more effort needs to be devoted to statistical analysis of IPL probability distributions based upon seat location, airplane type, and airplane version.

Some analysis of back-door IPL analysis was documented in RTCA/DO-233 for non-transmitting PEDs. This work was essentially republished in EUROCAE/ED-118. It is still unknown whether common mobile phones and FRS/GMRS radios, placed inches from aircraft wiring, may couple enough power into aircraft systems to cause EMI anomalies.

\section{Aeronautical Radio Receiver Susceptibility}

While aeronautical radio receiver sensitivity thresholds are well established, their susceptibility to different types of EMI signals is not understood. A standardized susceptibility measurement process for aircraft navigation radios needs to be developed. Multiple types of aircraft navigation radios should be characterized to establish database of typical susceptibility to EMI from present and future PEDs. Different susceptibility threshold requirements for navigation radios, based upon operational requirements (ie. minimum service levels and IFR conditions) should be developed.

\section{Operational Insight}

How pilots respond to various types of EMI events is largely unknown. In some cases, serious degradation of CNS data may be corrected by changing to a different channel, or switching the aircraft radio to a different antenna. To date, no commercial pilot training program exists to inform pilots about how to recognize EMI events and minimize their impact on the safely flying the airplane. EMI events that affect the interaction between flight crews and flight controllers in the overall CNS/ATM infrastructure need to be considered. Operational Insight becomes much more critical if an aircraft is subject to an EMI attack.

\section{B. Designing Solutions}

Due to the global interplay between CNS, ATM and new wireless technology development, it is especially important for government regulatory agencies and research organizations to collaborate extensively with airlines, airplane manufacturers, avionics manufacturers and wireless product manufacturers and standards organizations to develop solutions to current and future EMI problems. These EMI problems have both safety and security implications.

Table 1 shows a perspective on the new dynamics, concerns and solutions from the author's perspective. 
Table 1: EME and Aircraft: Dynamics, Concerns \& Solutions

\begin{tabular}{|c|c|c|c|}
\hline & Natural & Man-Made Inadvertent & Man-Made Malicious \\
\hline 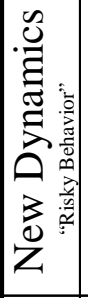 & $\begin{array}{l}\text {-Application of Composite } \\
\text { Materials to Airplanes } \\
\text { •High Altitude Flight } \\
\text {-UAV’s }\end{array}$ & $\begin{array}{l}\text { •CNS/ATM Increasingly Dependent } \\
\text { Upon Radio Technologies } \\
\text { •PED Technology: Ubiquitous } \\
\text {-RFID, UWB, IPV6, IEEE802.??? } \\
\text { •Spectrum Policy Evolution } \\
\text {-Spectrum on Demand } \\
\text {-Wireless Global Information Grid } \\
\text {-International Policy Variation }\end{array}$ & $\begin{array}{l}\text { •CNS/ATM Increasingly Dependent } \\
\text { Upon Radio Technologies } \\
\text { •HIRF weapon kits \& plans increasingly } \\
\text { available to the public } \\
\text { •Publicized Use of HIRF \& EMP } \\
\text { Weapons by Military/Government }\end{array}$ \\
\hline 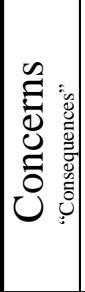 & $\begin{array}{l}\text {-Existing Certification and } \\
\text { modeling tools are not } \\
\text { adequate }\end{array}$ & $\begin{array}{l}\text {-EMI Events will Impact Aircrew } \\
\text { Operations More Frequently } \\
\text { •EMI Events are Difficult to Identify, } \\
\text { Repeat and Resolve }\end{array}$ & $\begin{array}{l}\text { •EMI techniques will be used to Exploit } \\
\text { CNS/ATM Infrastructure: COTs } \\
\text { Equipment; HIRF Kits \& Plans } \\
\text { •EMI Attack Option is “Sensational” } \\
\text {-Effective: Economic Impact, Media } \\
\text { Coverage, Public Confidence } \\
\text {-Anonymous: Difficult to ID Source } \\
\text {-Repeatable: Just add Electricity }\end{array}$ \\
\hline 里 & $\begin{array}{l}\text { •Neutron Particle Testing of } \\
\text { Avionics to identify } \\
\text { susceptibility } \\
\text { •Avionics Design for } \\
\text { Control of Upsets (VHM, } \\
\text { CUPR) }\end{array}$ & $\begin{array}{l}\text { •EMC Testing of New PED- } \\
\text { CNS/ATM technologies } \\
\text { •Collaboration with FCC, ITU, etc. } \\
\text { •Secure CNS, SASIF } \\
\text { •On-Board Spectrum Monitoring } \\
\text { •Crew Training to Identify \& Mitigate } \\
\text { EMI events } \\
\text {-Airplane Design for EMI Control } \\
\text { (VHM, CUPR, AVSI, RTCA, etc.) }\end{array}$ & $\begin{array}{l}\text { •Vulnerability Assessment of CNS/ATM } \\
\text { to HIRF Kits \& Plans and COTS Equip. } \\
\text { •Collaboration with DHS, DOD } \\
\text { •Secure CNS, SASIF } \\
\text { - On-Board Spectrum Monitoring } \\
\text { •Crew Training to Identify \& Mitigate } \\
\text { EMI attacks } \\
\text { •Commercial Airplane Design \& Test } \\
\text { Incorporates DOD EME Requirements }\end{array}$ \\
\hline
\end{tabular}

\section{Acknowledgments}

The majority of content in paper is a summary of works provided in the reference section. As such, the author acknowledges the contributions of the NASA LaRC HIRF Laboratory Team: Reuben A. Williams, Truong X. Nguyen, Sandra V. Koppen, Theresa Salud, George N. Szatkowski, Max Williams, and John H. Beggs; Delta Airlines: Kent Horton, Brian Eppic, Mitch Huffman, Harrison White; and the UWB Direct Effects Team: Gerald L. Fuller, Warren L. Martin, Timothy W. Shaver, John Zimmerman, William E. Larsen and James H. Hollansworth: the FAA Certification Office and Tech Center: Dave Walen, John Dimtroff and Anthony Wilson; and those who have supported the RTCA Special Committees on PEDs. NASA's contributions to this work are a direct result of funding from NASA's Aviation Safety and Security Program, with help from the FAA and the NASA HQ Office of Space Flight.

\section{Note}

The use of trademarks or names of manufacturers in this paper is for accurate reporting and does not constitute an official endorsement, either expressed or implied, of such products or manufacturers by the National Aeronautics and Space Administration.

\section{References}

${ }^{1}$ Fisher, F.A., Plumer, J. A. , Perala, R. A., Lightning Protection of Aircraft, Lightning Technologies Inc., 1990

2 RTCA/DO-119, "Interference to Aircraft Electronic Equipment From Devices Carried Aboard", Report from the Radio Technical Commission for Aeronautics Special Committee 88 Paper 39-63/119, April 12, 1963. 
${ }^{3}$ MIL-STD-461E, “DEPARTMENT OF DEFENSE INTERFACE STANDARD REQUIREMENTS FOR THE CONTROL OF ELECTROMAGNETIC INTERFERENCE CHARACTERISTICS OF SUBSYSTEMS AND EQUIPMENT”, August 20, 1999

4 MIL-STD-464A, "DEPARTMENT OF DEFENSE INTERFACE STANDARD ELECTROMAGNETIC ENVIRONMENTAL EFFECTS REQUIREMENTS FOR SYSTEMS”, December 19, 2002.

${ }^{5}$ RTCA/DO-160E, “Environmental Conditions and Test Procedures for Airborne Equipment”, Prepared by SC-135, December 9, 2004.

${ }^{6}$ Shooman, Martin L, “A study of occurrence rates of Electromagnetic Interference (EMI) to aircraft with a focus on HIRF (external) High Intensity Radiated Fields”, NASA-CR-194895, Apr 1, 1994 http://ntrs.nasa.gov/archive/nasa/casi.ntrs.nasa.gov/19940029450_1994029450.pdf

7 Ross, Elden, "Personal Electronic Devices and Their Interference With Aircraft Systems", NASA/CR-2001210866, June 2001, http://hdl.handle.net/2002/11736

8 Ross, Elden, "Personal Electronic Devices and Their Interference With Aircraft Systems", NASA/CR-2001210866, June 2001, http://hdl.handle.net/2002/11736

${ }^{9}$ Federal Communications Commission Rules and Regulations website. http://wireless.fcc.gov/rules.html, August 8, 2005.

10 CFR Title 14, Parts 91.21 and 121.306, "Use of Portable Electronic Devices Aboard Aircraft”, (Federal Airworthiness Regulations)

${ }^{11}$ RTCA/DO-160, “Environmental Conditions and Test Procedures for Airborne Equipment”, July $29,1997$.

${ }^{12}$ AC 91.21-1a (FAA Advisory Circular), "Use of Portable Electronic Devices Aboard Aircraft”, 10/02/2000

${ }^{13}$ Eurocae ED-14, "Environmental conditions and Test Procedures for Airborne Equipment, July, 1997.

${ }^{14}$ RTCA/DO-119, “Interference to Aircraft Electronic Equipment From Devices Carried Aboard”, Report from the Radio Technical Commission for Aeronautics Special Committee 88 Paper 39-63/119, April 12, 1963.

15 RTCA/DO-199, "Potential Interference to Aircraft Electronic Equipment from Devices Carried Aboard", Report from RTCA SC-156, 9/16/1988.

${ }^{16}$ RTCA/DO-233 “Portable Electronic Devices Carried on Board Aircraft”, Prepared by SC-177, August 20, 1996.

17 EUROCAE/ED-118, "Report on electromagnetic compatibility between passenger carried PEDs and aircraft systems”, From EUROCAE WG-58, November 2003

18 RTCA/DO-294, "Guidance on Allowing Transmitting Portable Electronic Devices (T PEDs) on Aircraft", Prepared By SC 202, October19, 2004

${ }^{19}$ Veda Report Number 79689-96U/P30041, “CV-580 Coupling Validation Experiment Report”, FAA Grant \#95-G007, November 15, 1996.

${ }^{20}$ Fuller, G. L., “747-222 Path Loss Test, Las Vegas, Nevada, Fall 1999”, “747-400 Path Loss Test, United Maintenance Center, San Francisco Airport, California, Fall 1999”, "Path Loss Measurements on Cylindrical Sections”, deliverable reports under NASA LaRC Contract L-10005, March 2000.

${ }^{21}$ Horton, Kent; Huffman, Mitch; Eppic, Brian; White, Harrison, “757 Path Loss Measurements”, NASA Center for AeroSpace Information (CASI)

NASA/CR-2005-213762, 20050601; June 2005

${ }^{22}$ Ely, J.J., Fuller, G. L., and Shaver, T. W., Ultrawideband Electromagnetic Interference to Aircraft Radios , 21st Digital Avionics Systems Conference, Irvine, California, October 27-31, 2002 http://techreports.larc.nasa.gov/ltrs/PDF/2002/mtg/NASA-2002-21dasc-jje2.pdf

${ }^{23}$ Ely, J.J., Fuller, G. L., and Shaver, T. W., Ultrawideband Electromagnetic Interference to Aircraft Radios--Results of Limited Functional Testing With United Airlines and Eagles Wings Incorporated, in Victorville, California , NASA/TM-2002-211949, October 2002, pp. 27

http://techreports.larc.nasa.gov/ltrs/PDF/2002/tm/NASA-2002-tm211949.pdf

24 Jafri, M. J., Ely, J. J., and Vahala, L., "Graphical Analysis of B-737 Airplane Pathloss Data for GPS and Evaluation of Coupling Mitigation Techniques”, 2004 IEEE International Symposium on Electromagnetic Compatibility, Santa Clara, California, August 9-13, 2004

http://techreports.larc.nasa.gov/ltrs/PDF/2004/mtg/NASA-2004-ieeeisec-mjj.pdf

${ }^{25}$ Jafri, M. J., Ely, J. J., and Vahala, L., Fuzzification of Electromagnetic Interference Patterns Onboard Commercial Airliners Due to Wireless Technology , 2004 IEEE International Symposium on Antennas and Propagation and 
USNC/URSI National Radio Science Meeting, Monterey, California, June 20-26, 2004 http://techreports.larc.nasa.gov/ltrs/PDF/2004/mtg/NASA-2004-ieeeisap-mjj.pdf

${ }^{26}$ Jafri, M. J., Ely, J. J., and Vahala, L., Graphical Representation of the Effects of Antenna Locations on Path Loss Data , 2003 IEEE International Symposium on Antennas and Propagation, Columbus, Ohio, June 22-27, 2003 http://techreports.larc.nasa.gov/ltrs/PDF/2003/mtg/NASA-2003-isap-mj.pdf

${ }^{27}$ Jafri, M. J., Ely, J. J., and Vahala, L., Graphical and Statistical Analysis of Airplane Passenger Cabin RF Coupling Paths to Avionics, 22nd Digital Avionics Systems Conference, Indianapolis, Indiana, October 12-16, 2003 http://techreports.larc.nasa.gov/ltrs/PDF/2003/mtg/NASA-2003-22dasc-mj.pdf

${ }^{28}$ Ely, J. J., Nguyen, T. X., Koppen, S. V., Beggs, J. H., and Salud, M. P.,"Wireless Phone Threat Assessment and New Wireless Technology Concerns for Aircraft Navigation Radios”, NASA/TP-2003-212446, July 2003

${ }^{29}$ Rosencrance, Linda, "Delta to use RFID tags to track luggage. The decision could save the airline up to \$100M annually”, Computerworld JULY 01, 2004.

${ }^{30}$ Ely, J.J., Fuller, G. L., and Shaver, T. W., Martin, W. L., Zimmerman, J., Fuschino, R. L., Larsen, W. E., “UWB EMI To Aircraft Radios: Field Evaluation on Operational Commercial Transport Airplanes”, NASA/TP-2005213606, January 2005.

${ }^{31}$ Kehs, Alan, Prepared Statement to the Joint Economic Committee Hearing on Radio Frequency Weapons and Proliferation, 2/25/1998. http://www.house.gov/jec/hearings/02-25-8h.htm

${ }^{32}$ Helfrick, A., and Wilson, A., "Investigations Into a System for the Detection and Location of Potentially Harmful Radiation from Portable Electronics Carried Onboard Aircraft”, IEEE/AIAA Digital Avionics Systems Conference Proceedings, November, 1998.

${ }^{33}$ De Donno, Capt. Fabio, "Portable Electronic Devices On Airplanes, Detection of Electromagnetic Interference On Board Of Aircraft, A Survey on Portable Phones Interference On Aircraft”, Presentation Charts, Seventh Flight Safety Conference, March 28-30, 2000.

${ }^{34}$ Veda Report Number 79689-96U/P30041, “CV-580 Coupling Validation Experiment Report”, FAA Grant \#95-G007, November 15, 1996.

35 Jafri, M. J., Ely, J. J., and Vahala, L., "Graphical Analysis of B-737 Airplane Pathloss Data for GPS and Evaluation of Coupling Mitigation Techniques”, 2004 IEEE International Symposium on Electromagnetic Compatibility, Santa Clara, California, August 9-13, 2004

http://techreports.larc.nasa.gov/ltrs/PDF/2004/mtg/NASA-2004-ieeeisec-mjj.pdf

36 FAA National Airspace System Operational Evolution Plan, Version 7.0, February 2005, http://www.faa.gov/programs/oep/

37 http://www.airborneinternet.com/

38 Joint E3 Bulletin, "DISA Emerging Spectrum Technology Program, Gearing up for Future Spectrum Technologies”, Volume 11, Issue 1 JANUARY 2005, A Publication of the U. S. Department of Defense 